\title{
MAPPING QTLS FOR YIELD AND YIELD COMPONENTS UNDER DROUGHT STRESS IN BREAD WHEAT (TRITICUM AESTIVUM L.)
}

\author{
FATIMA, S. ${ }^{*}-$ CHAUDHARI, S. K. ${ }^{2}-$ AKHTAR, S. ${ }^{1}-$ AMJAD, M. S. ${ }^{3}-$ AKBAR, M. ${ }^{1}-$ IQBAL, M. S. ${ }^{1}-$ \\ ARSHAD, M. $^{4}-$ SHEHZAD, T. \\ ${ }^{I}$ Department of Botany, Hafiz Hayat Campus, University of Gujrat, Pakistan \\ (e-mails:drsajjad.iqbal@uog.edu.pk; shamim.akhtar@uog.edu.pk; muhammad.akbar@uog.edu.pk) \\ ${ }^{2}$ Department of Botany, The University of Lahore, Sargodha Campus, Pakistan \\ (e-mail: sunbal.khalil@imbb.uol.edu.pk) \\ ${ }^{3}$ Department of Botany, Women University of Azad Jammu and Kashmir Bagh, Pakistan \\ (e-mail: malikshoaib1165@yahoo.com) \\ ${ }^{4}$ Department of Botany, PMAS Arid Agriculture University, Rawalpindi, Pakistan \\ (e-mail: arshad2uaar@yahoo.com) \\ ${ }^{5}$ Plant Genome Mapping Laboratory, University of Georgia, 111 Riverbend Road, Athens GA 30602 \\ (e-mail: shehzad@uga.edu) \\ *Corresponding author \\ e-mail: sammer.fatima@uog.edu.pk \\ (Received 20 ${ }^{\text {th }}$ Mar 2018; accepted $25^{\text {th }}$ May 2018)
}

\begin{abstract}
The aim of this study was to discover the geneic basis of drought tolerance, a double haploid mapping population, Drought Mapping Population 5 (DR. M.P. 5) was assessed for drought tolerance in hexaploid wheat (Triticum aestivum L.) under control and drought stress condition. The germplasm was planted under control and stress conditions. The yield and yield components were recorded. QTLs were detected by linking morphological data with genotypic data. Five drought tolerant wheat lines were found based on a thousand-grain weight, ranging from 49 to $62 \mathrm{~g}$. Novel Quantitative Trait Loci (QTLs) for spike length and grain per spike were identified during the present study. The novel QTLs are of great importance as these may be helpful in finding such regions in genome, which are responsible for drought tolerance contributing characteristics. The $\mathrm{D}$ genome is the main allele which denote drought tolerance to hexapoloid wheat while $\mathrm{A}$ and $\mathrm{B}$ genome in durum contribute the stress tolerant characteristics.
\end{abstract}

Keywords: SSR, DNA polymorphism, interval mapping, multiple QTL mapping, clustering of QTL

\section{Introduction}

Abiotic stress, such as drought not only interferes with the growth of plants (Tuberosa and Salvi, 2006) but also triggers several changes even at cellular level (Holmberg and Bulow, 1998). Further, it reduces nodes and internodes number; which reduces the height of plant (Ahmed et al., 2007). Drought prevails in Asian countries, and its severity can be observed in the arid and semi-arid areas, creating massive losses to their agricultural economics (Huaqi et al., 2002). Drought stress affects the rate of transpiration and ultimately plants may start wilting. Particularly in wheat, the developmental stages are also affected by drought (Wahid et al., 2007). Usually plants grow normally under favorable conditions, but if plants are exposed to any kind of stress, then it is natural that they complete their life cycle rapidly and escape the stress (Fischer, 1985; Hossain et al., 2009, 2011, 2012a, b, c, Hakim et al., 2012; Nahar et al., 2010). Further in moistureaffected areas, late sowing results in yield reduction of wheat and as a result, early sowing 
is the common practice in drought prone areas such as Pakistan, India and Bangladesh to avoid drought and heat stress (Mahboob et al., 2005; Din and Singh, 2005).

Common wheat (Triticum aestivum L.) is originated from three different genomes. Each genome has three groups of chromosomes: A, B and D. The genome size of the hexplaoid is $16 \times 10^{9}$ bp per chromosome (Bennett and Smith, 1976). As wheat is a major staple food and its intake is growing day by day, there will be approximately a double quantity of wheat grain required by the next fifty years (Rajaram, 2001; Mujeeb-Kazi and Rajaram, 2002). To meet the increasing demand, genetic resources can play a vital role both locally as well as globally, ultimately supporting agricultural economies worldwide (Rajaram, 2001). Significant work was accomplished in the past by synthesizing the bread wheat by crossing durum and Ae. tauschii $(2 \mathrm{n}=14)$ and then duplicating its chromosome Mujeeb-Kazi (2000). By crossing the T. turgidum $(2 \mathrm{n}=28)$ with a variety of Ae. tauschii, stress tolerance was ultimately enhanced in synthetic wheat. Ae. tauschii is the $\mathrm{D}$ genome donor and enhances drought tolerance in bread wheat (Del Blanco et al., 2000, 2001; Schmidt et al., 2005). Hexaploid wheat is the most essential cereal crop in the world and the chief staple food of Pakistan. It is paramount to increase the production of wheat by $70 \%$ globally to meet the nutritional demands by 2050 (Ray et al., 2013). As wheat is the staple of Pakistan, it occupies the central position in the agricultural policies of the country. Wheat contains $55 \%$ carbohydrate, which equals to $20 \%$ food calories. Pakistan is ranked ninth in wheat production. The bread wheat production was noted in 2010 to 2012 as 23.3, 25 and 23.5 million tons respectively (GOP, 2012). According to the Pakistan Bureau of Statistics, the world wheat production in 2016-17 was 749 million tons. Pakistan's statistical data of wheat reveal that the amount of cultivated land is 9.05 $\mathrm{m}$ ha, the total production is 25 million tons and the yield is 2.78 tons/ha (GOP, 2017).

DNA polymorphisms play a crucial role in unveiling Simple Sequence Repeats (SSRs) derived from Triticeae. The genomic relationship among various traits in wheat was identified by using SSR (Dreisigacker et al., 2004; Sun et al., 1998). For QTL analysis, a linkage map is required and by linking the genotypic and phenotypic data, QTLs can be find out (McCouch and Doerge, 1995). SSR markers could be used to measure agronomic traits of concern, which minimize the cost and time of quantitative trait loci analyses (Young, 1996; Ijaz and Khan, 2009). The current research was planned for QTL mapping in drought mapping population 5 (DR MP 5) by linking the genotypic and phenotypic data.

\section{Material and methods}

\section{Plant material}

The mapping population consists of two parents that is Opata and SH349 and eightyfour individuals of doubled haploids. The pedigree is Opata // Decoy (DOY) / Ae. tauschii (Ae. squarrosa) \{458\}. Ae. tauschii was assigned 458 accession number. Opata (bread wheat) is a high yielding cultivar and is drought sensitive while SH349 is synthetic hexaploid wheat and has drought tolerance properties.

\section{Soil type and agriculture practices}

These eighty-four individuals with parents were planted at the Wheat Wide Crosses Program in the National Agriculture Research Center (NARC) in Islamabad, Pakistan. Two treatments were control (fully irrigated) and a drought stress treatment was in a tunnel. To protect it from precipitation, plot for stress treatment was sheltered with plastic 
sheets sustained on iron rods of the tunnel. Water was suspended at flowering in the middle of March. The site of experiment originates from the upland part of potohar, confined in Gujranwala type soil series (Location 6; Rashid et al., 1994). This soil is comprised of well-drained, deep and temperately fine-textured units. It is non-saline, somewhat calcareous; its $\mathrm{pH}$ is 8.1 with $0.24 \mathrm{dS} / \mathrm{m}$ electrical conductivity (EC). In order to provide ample nutrition, standard agronomical practices were carried out.

Healthy seeds were selected for sowing. Seeds were surface sterilized by using $1 \%$ mercuric chloride for 5-7 minutes and, then washed carefully with distilled water. Petri plates were used for seeds germination in the dark for two days on wet filter paper while monitoring temperature. The healthy seedlings were shifted to jiffies containing humus for auxiliary growth. The seedlings of equal height (six days old) were transferred to the field and tunnel. Drought stress was enforced at pre-anthesis period, where water was withheld for 70-90 days. For control treatment, regular mode of irrigation was maintained. Soil humidity was checked by using the Time-Domain Reflectometer (TDR), a soil moisture meter. The control showed a $25 \%$ soil moisture, which dropped to $13 \%$ under the drought-stressed conditions.

\section{Experimental design}

RCBD (Randomized Complete Block Design) was applied in tunnel as well as in field for control and drought treatment observations. Each row was two meters long. A distance of $30 \mathrm{~cm}$ was maintained for inter row spacing. After sowing, the yield and yield components were recorded during the experiment such as Plant height (measured in $\mathrm{cm}$ ) $(\mathrm{PH})$, Days to heading (DH), (measured in numbers), Days to physiological maturity (DPM), (measured in numbers), Spike length (measured in $\mathrm{cm}$ ) (SL), Grain per spike $(\mathrm{G} / \mathrm{S})$ and Thousand Grain weight (measured in gm) (TGW). Statistical analysis was performed through the software Statistica.

\section{Extraction, polymerization and electrophoresis of DNA}

Fatima et al. (2014) published the map under consideration; it was of a double haploid mapping population (DR. M.P.5). According to that published data, the DNA of parental lines (Opata and SH349) and the whole mapping population were extracted (Sharp et al., 1988). Fresh leaves were used for this purpose. The extracted DNA was stored at $-20{ }^{\circ} \mathrm{C}$. The florimeter was used for the quantification of DNA. (The Qubit fluorometer is a small instrument used for quantification of DNA, RNA, and protein and used in many different applications.) The Qubit fluorometer uses fluorescent dyes to determine the concentration of nucleic acids and proteins in a sample. The robotic station was used for the normalization of DNA at $20 \mathrm{ng} / \mu \mathrm{l}$. The robotic station is a fully automatic system, which is used to dilute the DNA samples with more accuracy and speed.

The SSR markers are used for the genotyping of parental lines and for the whole mapping population. The SSR markers were selected based on the literature cited. The SSR were selected in such a way that they cover the entire genome of the wheat. 174 SSRs were used during the present study. By using PCR, the parental line genomes were amplified and after this, parental peaks were identified by using capillary sequencer. The selected polymorphic markers were used to detect the polymorphism in the entire mapping population. Seventy-nine polymorphic SSRs genomic loci were applied overall mapping population to detect the QTLs. The following markers were used, WMC (Gupta et al., 2002); GWM (Roder et al., 1998); MGBE and TaPGAM (Xue et al., 2008), STS- 
PSR (Xue et al., 2008), SWES (Peng and Lapitan, 2005), BARC (Song et al., 2005), MAG (Xue et al., 2008), CFD (Guyomarc'h et al., 2002) and CFA (Sourdille et al., 2003). The mixture, which was used for PCR, consisted of DNA, dNTPs, buffer, forward and reverse primer, DMSO, water and DNA taq polymerase. Roder et al. (1998) prescribed conditions were followed for PCR reaction. Alleles having difference of at least two base pairs with reference to amplified product were selected for polymorphic marker. The difference up to one base pair is difficult to predict so it is ignored during analysis (Jones et al., 1997). The Capillary electrophoresis is an analytical technique that separates ions based on their electrophoretic mobility with the use of an applied voltage, is a better instrument to find out polymorphism than the gel electrophoresis. Highest quality data can be obtained at low cast per sample. Fluorescent primers such as FAM, HEX, NED and TET were used to see the peaks and peaks were recorded at $500 \mathrm{~nm}$ absorbance maximum. The GeneMapper 4 was used to separate the electropherograms. To save time and money, primers were run simultaneously, which have different colors of electropherograms.

The JoinMap 4 software (Van Ooijen and Voorips, 2004) was used to construct the map with a minimum LOD value 4 by using the Kosambi mapping function. This map was developed by taking Opata and SH349 as having contrasting characteristics of interest. This map was constructed by using 79 PCR based polymorphic genomic loci. Chi-square test was used for all loci for verification of goodness of fit to an estimated value 1:1. Sixteen linkage groups were obtained. Previous published wheat maps were used to associate the linkage groups to the chromosomes of wheat (Somers et al., 2004).

\section{Statistical analysis and QTL detection}

Analysis of variance, frequency distribution and Pearson correlation were determined by using Statistix. Genotypes, which have $\alpha 0.5$ values, were differentially different from each other and significant interaction was found between the treatments and the genotypes. The JoinMap4 and the MapQTL 5 were used to analyze the molecular diagnostics (Van Ooijen, 2004). The generated data were entered on an Excel sheet as As (parent A type) and Bs (parent B type). To construct the linkage map, JoinMap4 was used and data was analyzed (Van Ooijen and Voorips, 2004). The computer program MapQTL 5 was used to link the morphho-physiological and genotypic data to find out QTLs. Corel draw 4 and Map chart were used to draw the QTLs on chromosomes. Permutation test was used to check the LOD value. Threshold levels were determined by using $\mathrm{P}<0.05$ for the comparison of 1000 data permutations which is suitable for assessing critical thresholds at $\alpha=0.10$, and $\alpha=0.05$ (Churchill and Doerge, 1994). First, Interval Mapping (IM) was used to find the major QTLs. After finding the major QTLs, Multiple QTL Mapping (MQM) was applied to find more precise results.

\section{Results}

\section{Phenotypic analysis of drought tolerance}

The phenotypic data for yield and yield components was recorded (Fig. 1). Opata, SH349 and the DHs displayed high phenotypic variation for these traits. Opata and SH349 performed distinctly in all observations. Throughout the study, certain characters reduced under water stress e.g. the PH reduced by $15.26 \%$, the SL reduced by $15 \%$, the number of $\mathrm{G} / \mathrm{S}$ reduced by $62.34 \%$ and the TGW reduced by $35.80 \%$ respectively. 

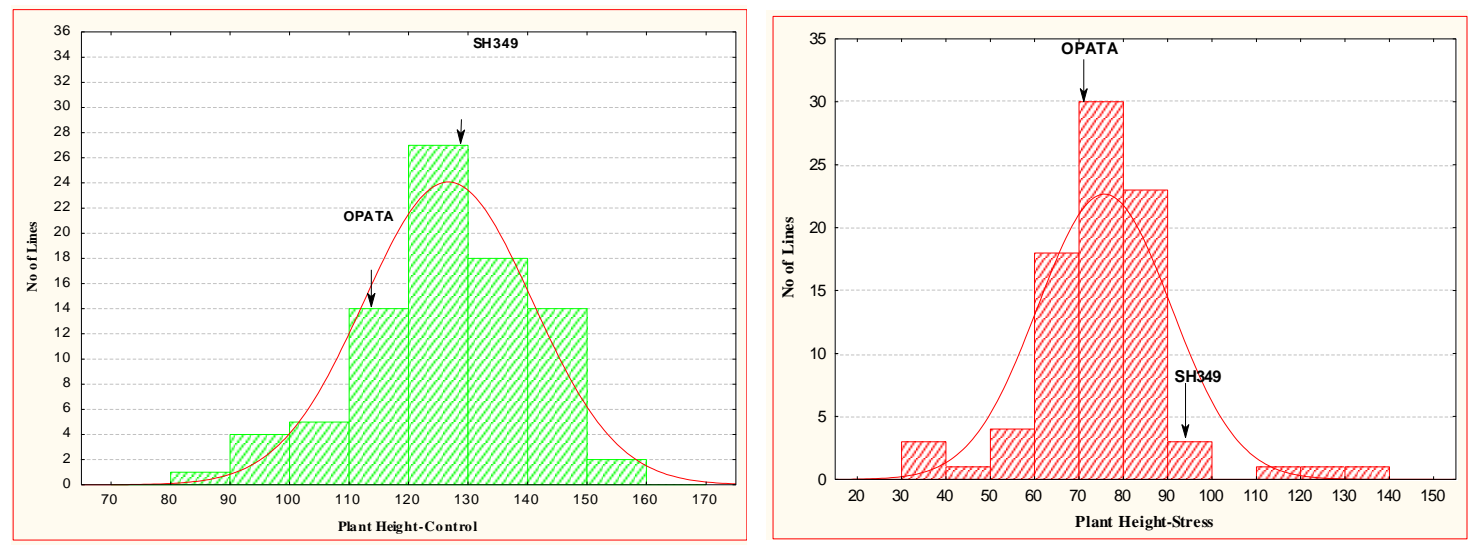

a
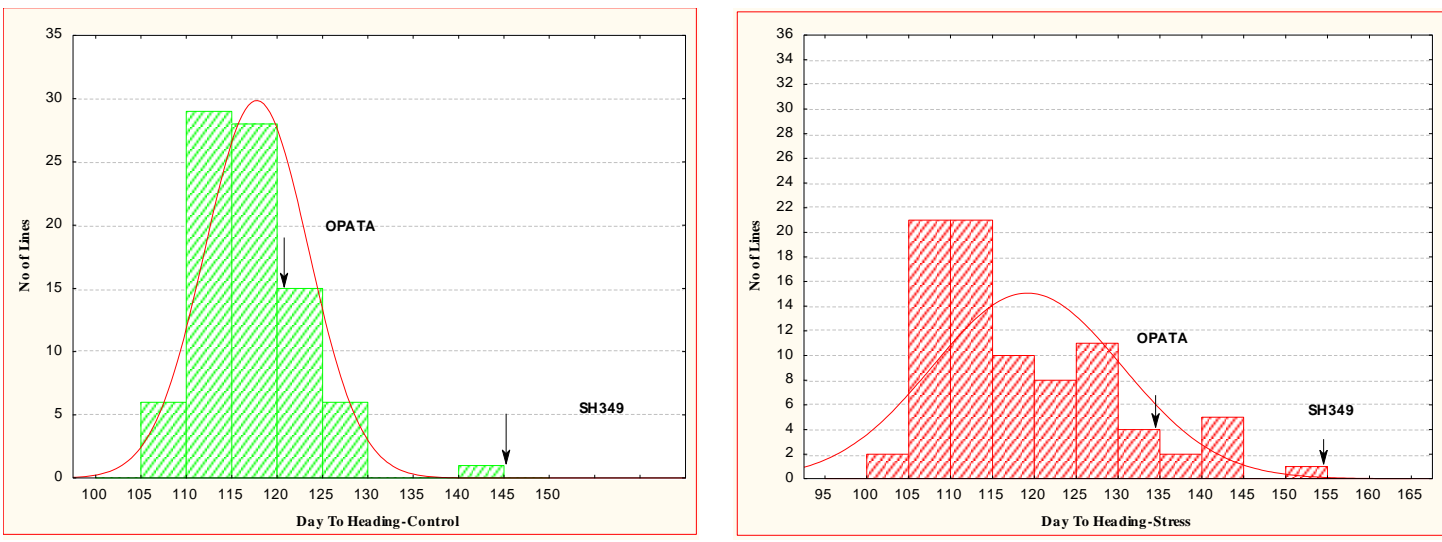

b
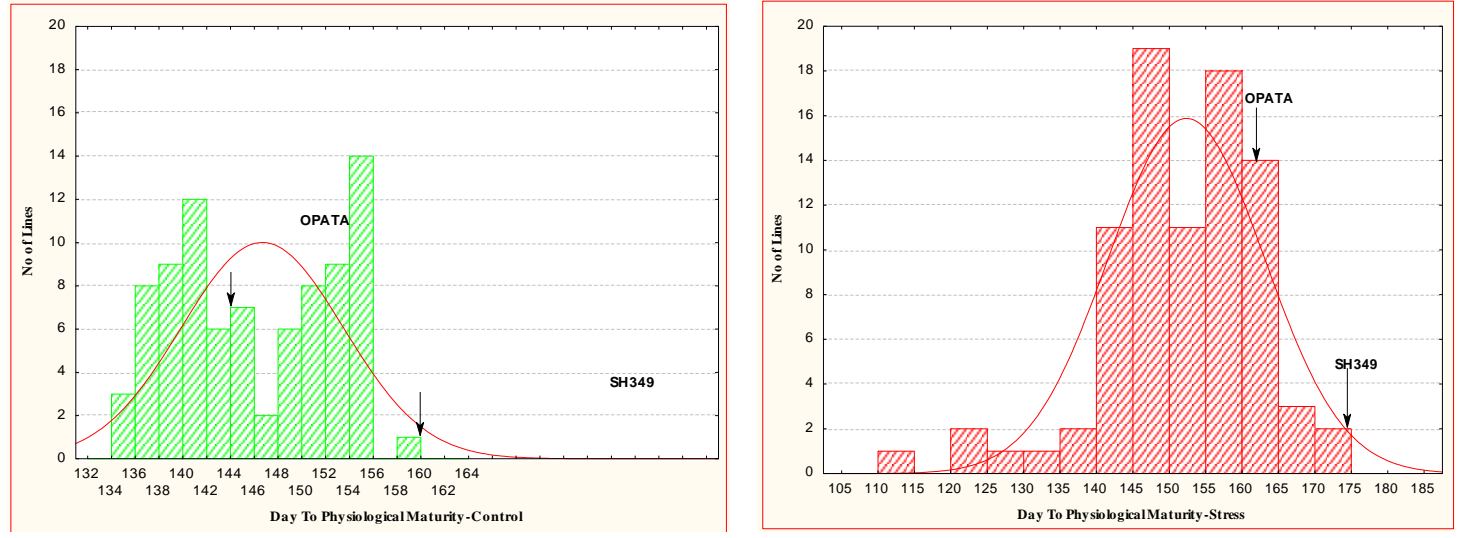

c
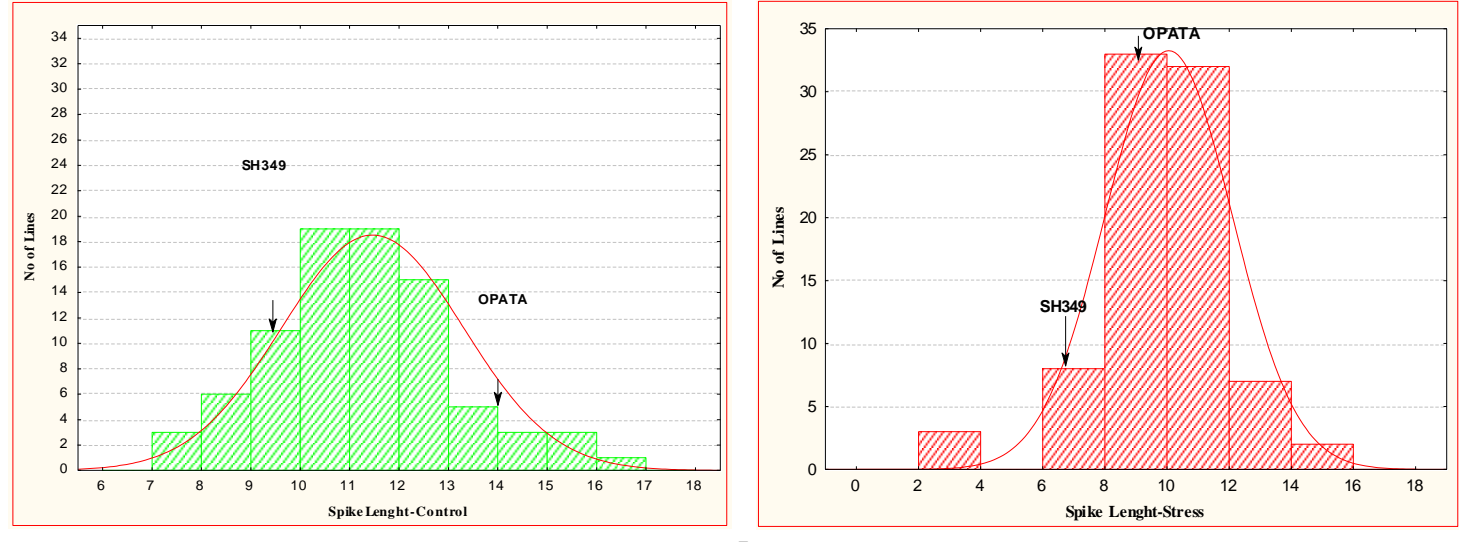

d

APPLIED ECOLOGY AND ENVIRONMENTAL RESEARCH 16(4): 4431-4453.

http://www.aloki.hu • ISSN 15891623 (Print) • ISSN 17850037 (Online)

DOI: http://dx.doi.org/10.15666/aeer/1604_44314453

(c) 2018, ALÖKI Kft., Budapest, Hungary 

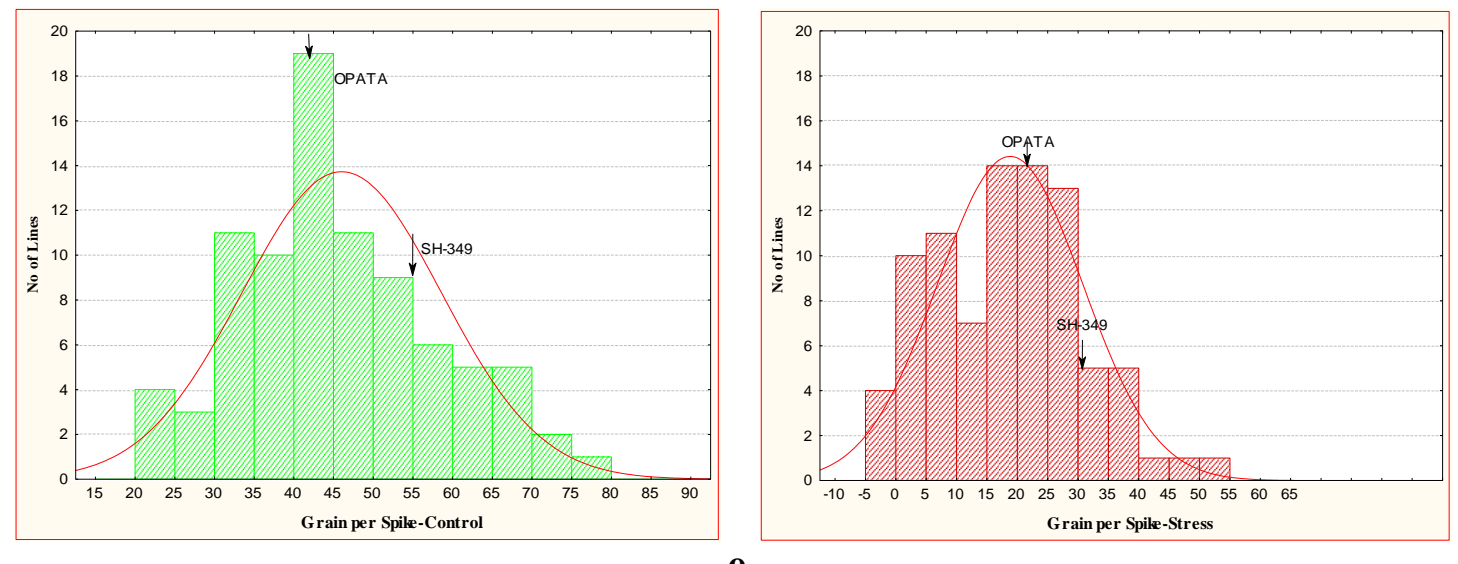

e
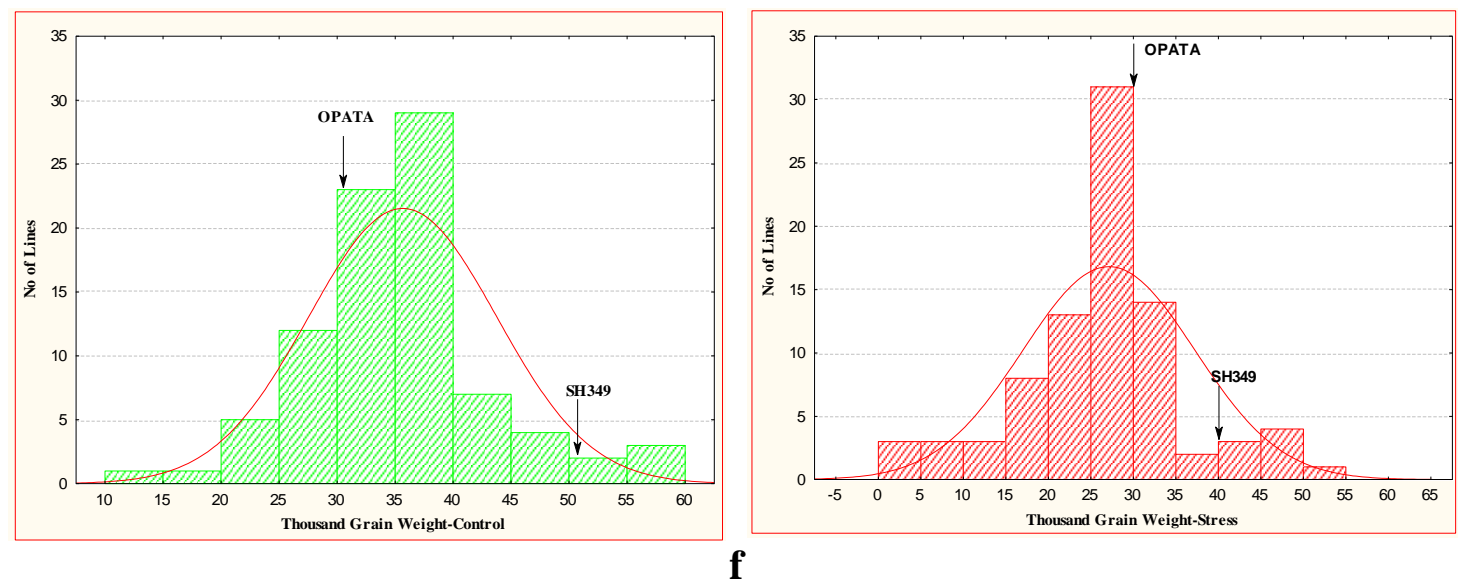

Figure 1. (a) Histogram of phenological attributes of plant height (cm) in field and in tunnel (PH-C and PH-S). (b) Histogram of phenological attributes of days to heading (n) in field and in tunnel (DH-C and DH-S). (c) Histogram of phenological attributes of days to physiological maturity ( $n$ ) in field and in tunnel (DPM-C and DPM-S). (d) Histogram of phenological attributes of spike length (cm) in field and in tunnel (Sp.L-C and Sp.L-S). (e) Histogram of phenological attributes of grain per spike (n) in field and in tunnel $(G / S-C$ and $G / S-S)$. (f) Histogram of phenological attributes of thousand grain weight $(\mathrm{gm})$ in field and in tunnel

( $T G W-C$ and $T G W-S)$

\section{Correlations}

Significant correlation was found between $(\mathrm{DH})$ and $(\mathrm{DPM})$ with $\mathrm{r}$-value $=0.7613$ (Table 1). Further significant correlation was found between (DH) and (DPM) with $r=0.8210$ value under water stress condition that indicates delay in heading that leads to delay in days to physiological maturity. The $\mathrm{PH}$ is a genetically controlled character and varies with environmental conditions and genotype. Under water stress condition PH has significant and positive correlation with DH and DPM with values $r=0.2276$ and 0.3766 . The SL has positive and significant correlation with DPM with a value $\mathrm{r}=0.2570$. Values $\mathrm{r}=0.2644,0.4340$ and 0.5608 were found for spike length, $\mathrm{DH}$ and DPM under drought stress. Values for correlation, $r=0.4688$ and 0.2149 were recorded for $\mathrm{G} / \mathrm{S}, \mathrm{PH}$ and SL respectively. Values $\mathrm{r}=0.2389,0.4330,0.3791$ and 0.5354 were found for DPM, PH, SL and G/S. 
Table 1. Correlation of yield and yield components under control and stress conditions

\begin{tabular}{|c|c|c|c|c|c|c|c|}
\hline Trait & Treatment & DH & DPM & PH & SL & G/S & TGW \\
\hline \multirow[t]{4}{*}{ DH } & Control & 1.0000 & & & & & \\
\hline & & $\mathrm{p}=---$ & & & & & \\
\hline & Stress & 1.0000 & & & & & \\
\hline & & $\mathrm{p}=---$ & & & & & \\
\hline \multirow[t]{4}{*}{ DPM } & Control & .7613 & 1.0000 & & & & \\
\hline & & $\mathrm{p}=.000$ & $\mathrm{p}=---$ & & & & \\
\hline & Stress & .8210 & 1.0000 & & & & \\
\hline & & $\mathrm{p}=0.00$ & $\mathrm{p}=---$ & & & & \\
\hline \multirow[t]{4}{*}{$\mathbf{P H}$} & Control & -.2319 & -.1351 & 1.0000 & & & \\
\hline & & $\mathrm{p}=.032$ & $\mathrm{p}=.215$ & $\mathrm{p}=---$ & & & \\
\hline & Stress & .2276 & .3766 & 1.0000 & & & \\
\hline & & $\mathrm{p}=.035$ & $\mathrm{p}=.000$ & $\mathrm{p}=---$ & & & \\
\hline \multirow[t]{4}{*}{ Sp.L } & Control & .1910 & .2570 & .1990 & 1.0000 & & \\
\hline & & $\mathrm{p}=.078$ & $\mathrm{p}=.017$ & $\mathrm{p}=.066$ & $\mathrm{p}=---$ & & \\
\hline & Stress & .2644 & .4340 & .5608 & 1.0000 & & \\
\hline & & $\mathrm{p}=.014$ & $\mathrm{p}=.000$ & $\mathrm{p}=.000$ & $\mathrm{p}=---$ & & \\
\hline \multirow[t]{4}{*}{ G/S } & Control & .0071 & -.0739 & -.0544 & .0274 & 1.0000 & \\
\hline & & $\mathrm{p}=.948$ & $\mathrm{p}=.499$ & $\mathrm{p}=.619$ & $\mathrm{p}=.802$ & $\mathrm{p}=---$ & \\
\hline & Stress & -.0932 & .0836 & .4688 & .2149 & 1.0000 & \\
\hline & & $\mathrm{p}=.394$ & $\mathrm{p}=.444$ & $\mathrm{p}=.000$ & $\mathrm{p}=.047$ & $\mathrm{p}=---$ & \\
\hline \multirow[t]{4}{*}{ TGW } & Control & -.1272 & -.1388 & .2954 & .1962 & .1684 & 1.0000 \\
\hline & & $\mathrm{p}=.243$ & $\mathrm{p}=.203$ & $\mathrm{p}=.006$ & $\mathrm{p}=.070$ & $\mathrm{p}=.121$ & $\mathrm{p}=---$ \\
\hline & Stress & -.0349 & .2389 & .4330 & .3791 & .5354 & 1.0000 \\
\hline & & $\mathrm{p}=.750$ & $\mathrm{p}=.027$ & $\mathrm{p}=.000$ & $\mathrm{p}=.000$ & $\mathrm{p}=.000$ & $\mathrm{p}=---$ \\
\hline
\end{tabular}

DH (Days to Heading), DPM (Days to Physiological Maturity), PH (cm) (Plant Height), Sp.L.(cm) (Spike length), G/S (n) (Grain per Spike), TGW (gm) (Thousand Grain Weight)

\section{QTLs detected by interval mapping (IM)}

Interval mapping was used to detect QTL and data are shown in Table 2 and Figure 2. Four QTLs for DH were detected in the field experiments with LOD values 7.69, 3.89, 1.91 and 2.00 respectively on the 6A chromosome. A QTL for DPM was detected by interval mapping in field experiments, located on 1B having a LOD score 3.06 with very high phenotypic variation i.e. $80.4 \%$ and allele contributed by SH349 for this QTL. LOD values 2.31 and 2.43 were found for two QTLs located on the 6A and the 7B chromosomes for G/S. A QTL was detected by interval mapping having a LOD value 2.14 under drought stress condition on 5A chromosome. Under control conditions, a QTL having LOD value 2.02 was detected on 6A chromosome for SL. 
Table 2. QTLs detected by interval mapping of a DH population Opata $\times$ SH349. QTL were identified by interval mapping and significance was recognized at an LOD threshold following 1,000 permutations (in brackets) (different threshold for each trait). Size of the effect and phenotypic variation explained $\left(R^{2}\right)$ are also presented

\begin{tabular}{|c|c|c|c|c|c|c|c|c|c|}
\hline $\mathrm{Sr} \#$ & Name of QTL & QTL interval $^{\mathrm{a}}$ & Peak marker & $\mathrm{Chr}^{\mathrm{b}}$ & Trait & Env & LOD & Adtv eft ${ }^{c}$ & $\mathbf{R}^{2}(\%)^{\mathbf{d}}$ \\
\hline 1 & QDH.C.IM.wwc-2D.I & wmc453b-gwm515b & wmc453b & $2 \mathrm{D}$ & $\mathrm{DH}$ & Field & $\begin{array}{l}7.69 \\
(3.4)\end{array}$ & 2.88 & 34.8 \\
\hline 2 & QDH.C.IM.wwc-2D.2 & wmc630e-gwm515a & wmc630e & $2 \mathrm{D}$ & $\mathrm{DH}$ & Field & 3.89 & -2.4 & 21.4 \\
\hline 3 & QDH.C.IM.wwc-6A.3 & gwm1017a-gwm1017b & gwm1017a & $6 \mathrm{~A}$ & $\mathrm{DH}$ & Field & 1.91 & 2.99 & 37.1 \\
\hline 4 & QDH.C.IM.wwc-6A.4 & gwm1089b-gwm1089a & gwm1089b & $6 \mathrm{~A}$ & DH & Field & 2.00 & -3.41 & 44.6 \\
\hline 5 & QDPM.C.IM.wwc-IB.I & gwm153e-wmc611c & gwm153e & 1B & DPM & Field & $\begin{array}{c}3.06 \\
(3.56)\end{array}$ & -5.98 & 80.4 \\
\hline 6 & QG/S.C.IM.wwc-6A.I & gwm1017a-gwm169 & gwm1017b & $6 \mathrm{~A}$ & $\mathrm{G} / \mathrm{S}$ & Field & $\begin{array}{c}2.31 \\
(2.89)\end{array}$ & -4.81 & 13.9 \\
\hline 7 & QG/S.C.IM.wwc-7B.2 & gwm146c-gwm146b & gwm146a & $7 \mathrm{~B}$ & $\mathrm{G} / \mathrm{S}$ & Field & 2.43 & -4.55 & 13.1 \\
\hline 8 & QTGW.S.IM.wwc-5A & wmc630c-wmc630b & wmc630c & $5 \mathrm{~A}$ & TGW & Tunnel & $\begin{array}{l}2.14 \\
(2.2)\end{array}$ & 7.97 & 59.5 \\
\hline 9 & QSp.L.C.IM.wwc-6A.I & gwm1017a-gwm1017b & gwm1017a & $6 \mathrm{~A}$ & Sp-L & Field & $\begin{array}{c}2.02 \\
(2.56)\end{array}$ & -0.68 & 14 \\
\hline
\end{tabular}

a: Marker interval where the QTL has been detected. b: Chr Chromosome. c: Effects on the examined characters of the alleles from the 'Opata'. $\mathrm{d}$ : R2 (\%) is the quantity of phenotypic variation clarified by the QTL

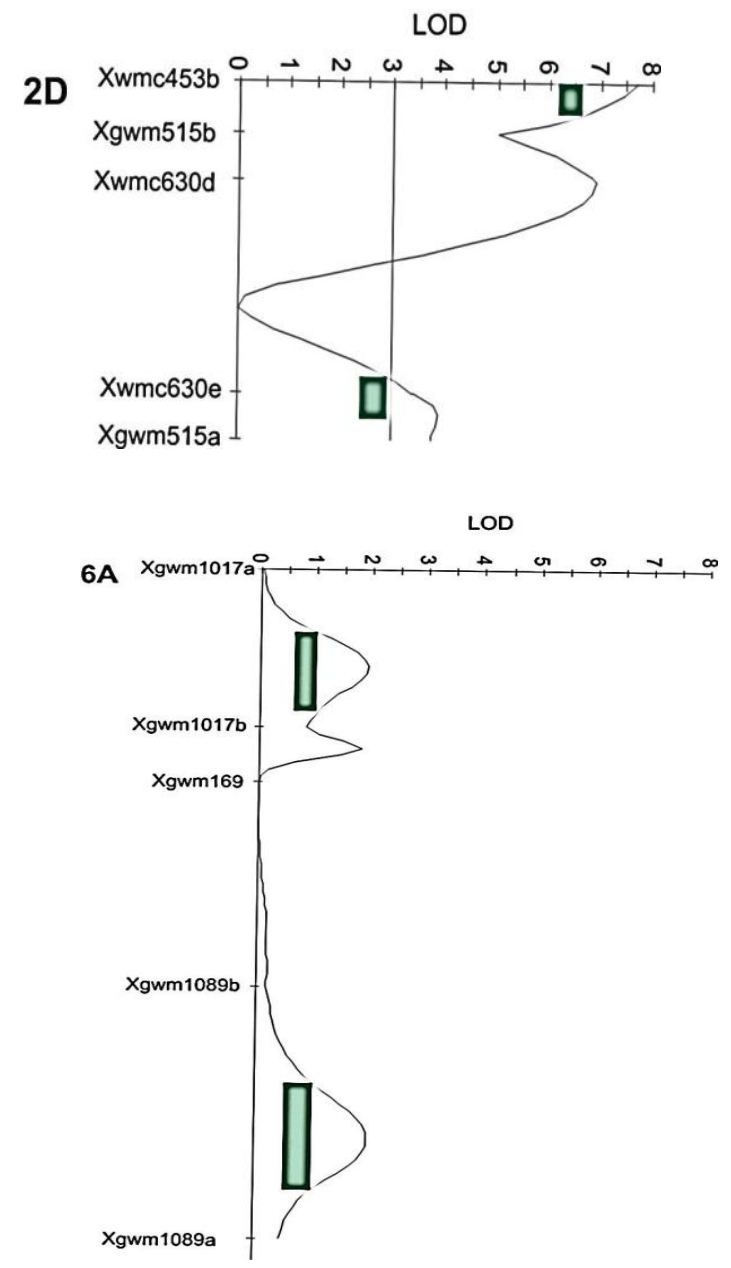


LOD

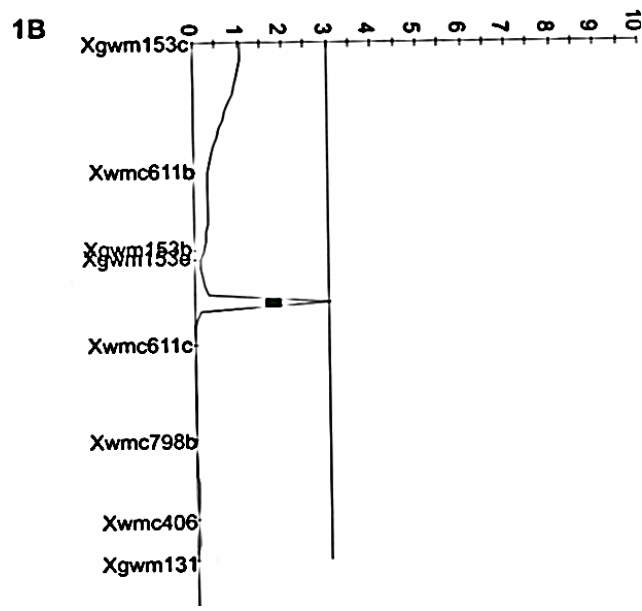

b

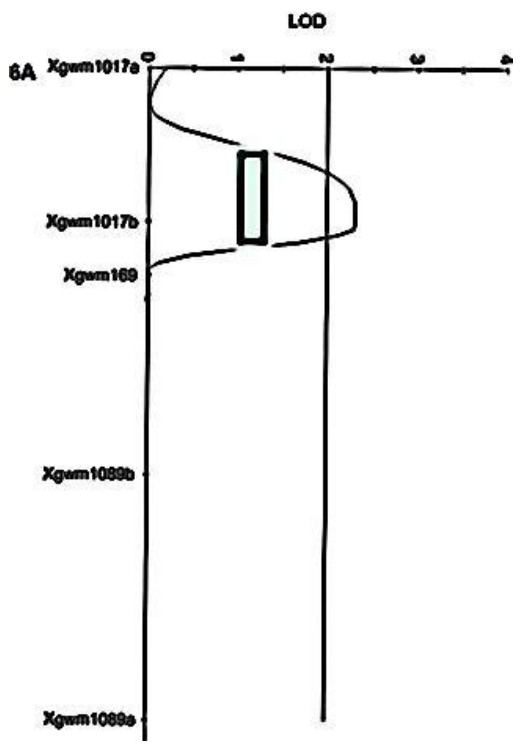

LOD

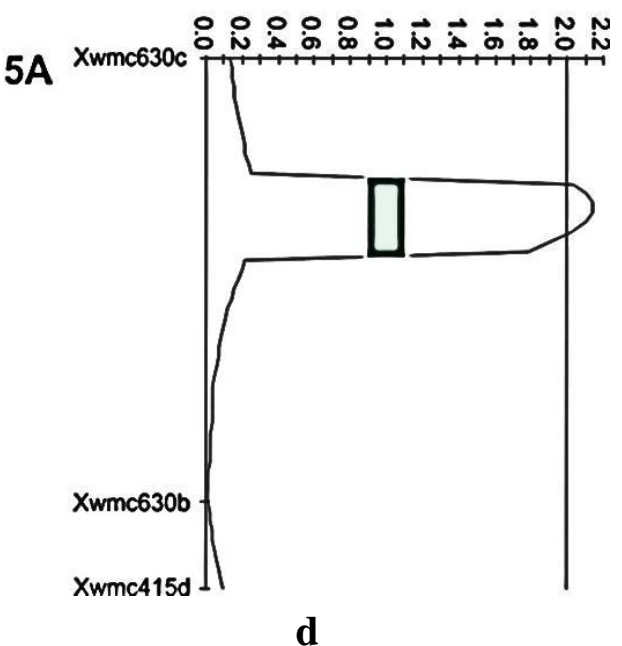

c
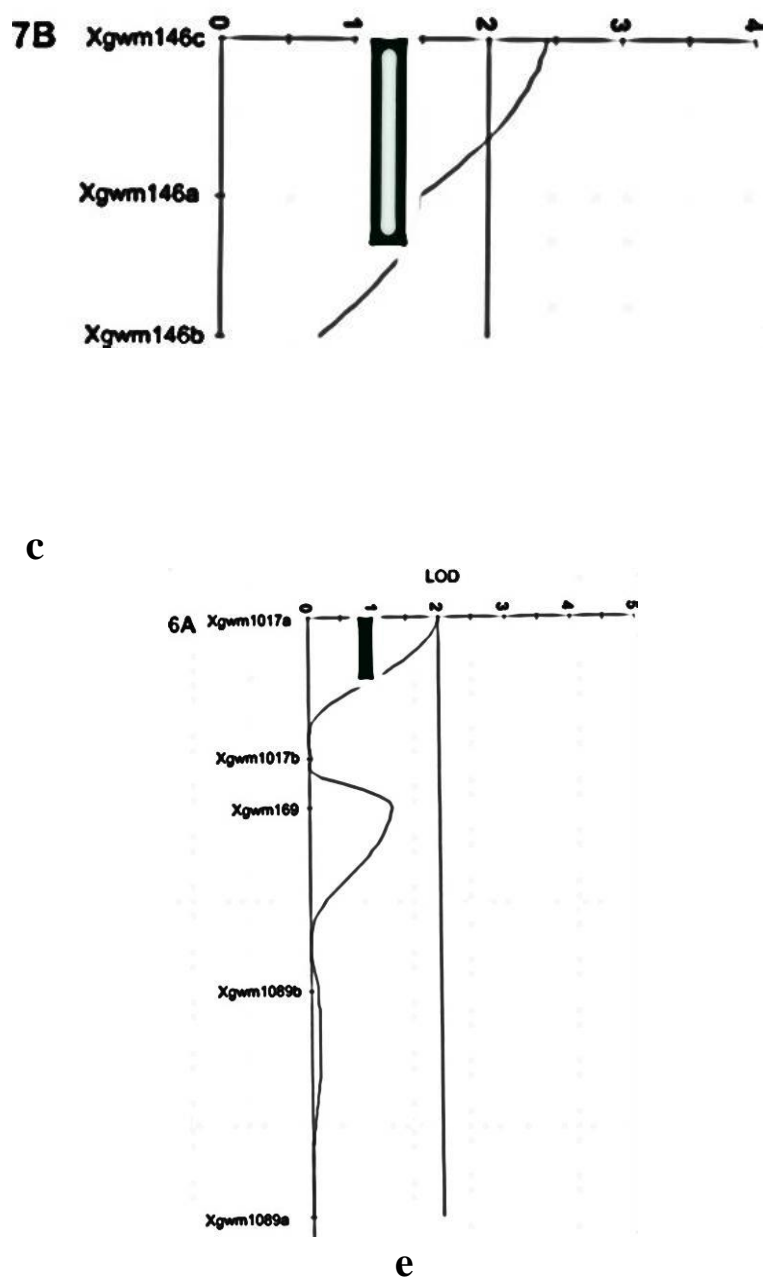

Figure 2. Interval Mapping (IM) for the 84 DHs population. (a) Days to heading-field. (b) QTLs for days to physiological maturity-field. (c) Grain per spike-field. (d) Thousand grain weight-stress. (e) Spike length-field 


\section{QTLs detected by multiple QTL mapping (MQM)}

Data detected by Multiple QTL Mapping is shown in Table 5 and Figure 3. Two QTLs for days to heading were detected by MQM in field (control) and tunnel (drought stress) trials, on a 2D chromosome, with LOD values 6.93 and 3.14. A major QTL for DPM was found by MQM mapping under control conditions, on 2D chromosome with LOD value 9.39. For SL, a major QTL was found on 4A chromosome under control conditions. For SL, a second QTL was detected on 7A chromosome under water stress with 4.93 LOD value. A LOD value 2.15 was found for TGW under water stress condition. Two QTLs with LOD values 3.98 and 2.41 were found under control and stress conditions on $6 \mathrm{~A}$ and $1 \mathrm{~B}$ chromosomes.
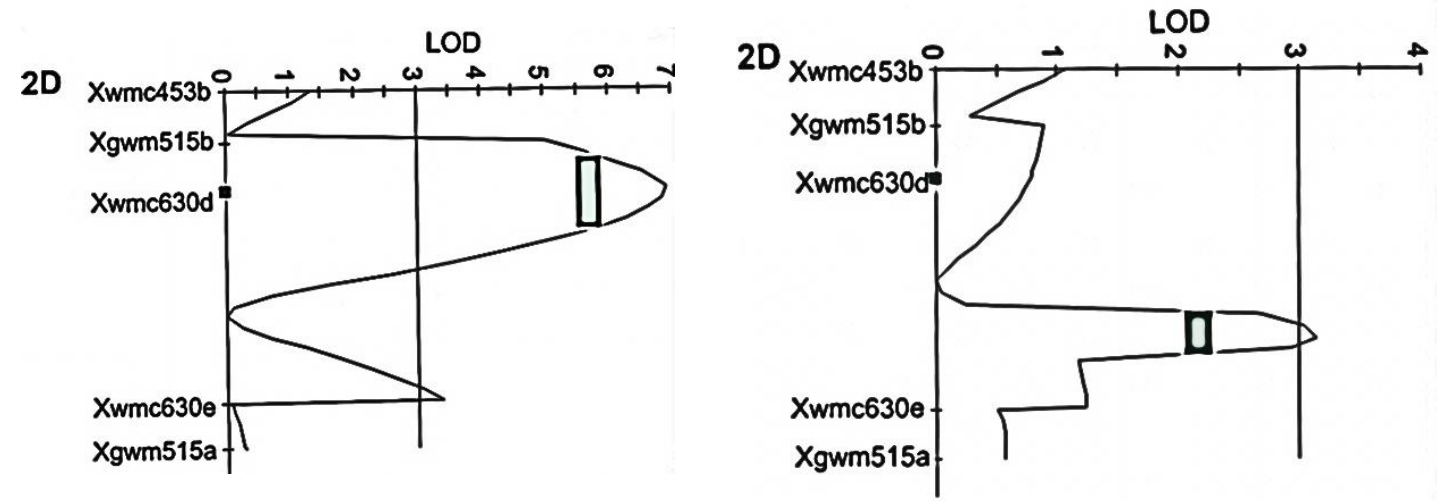

$\mathbf{a}$

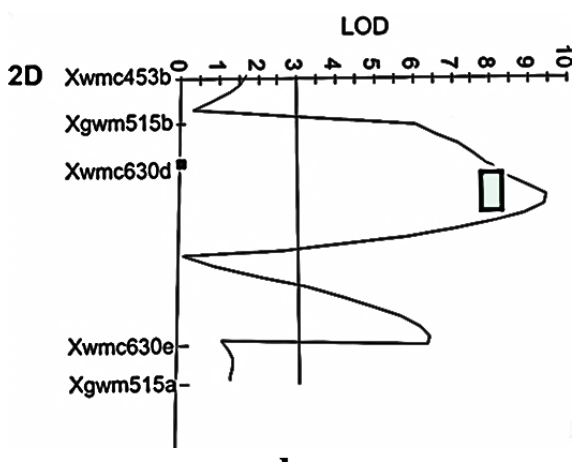

b
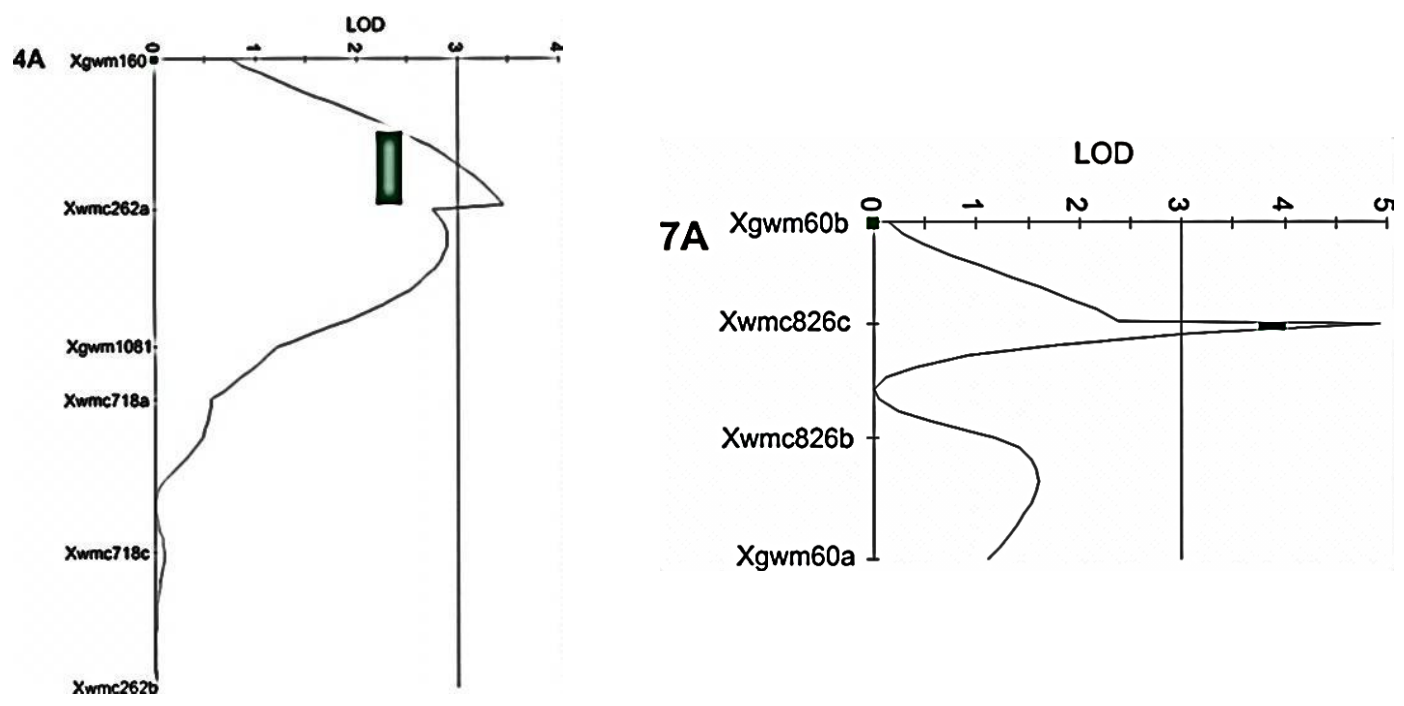

c 


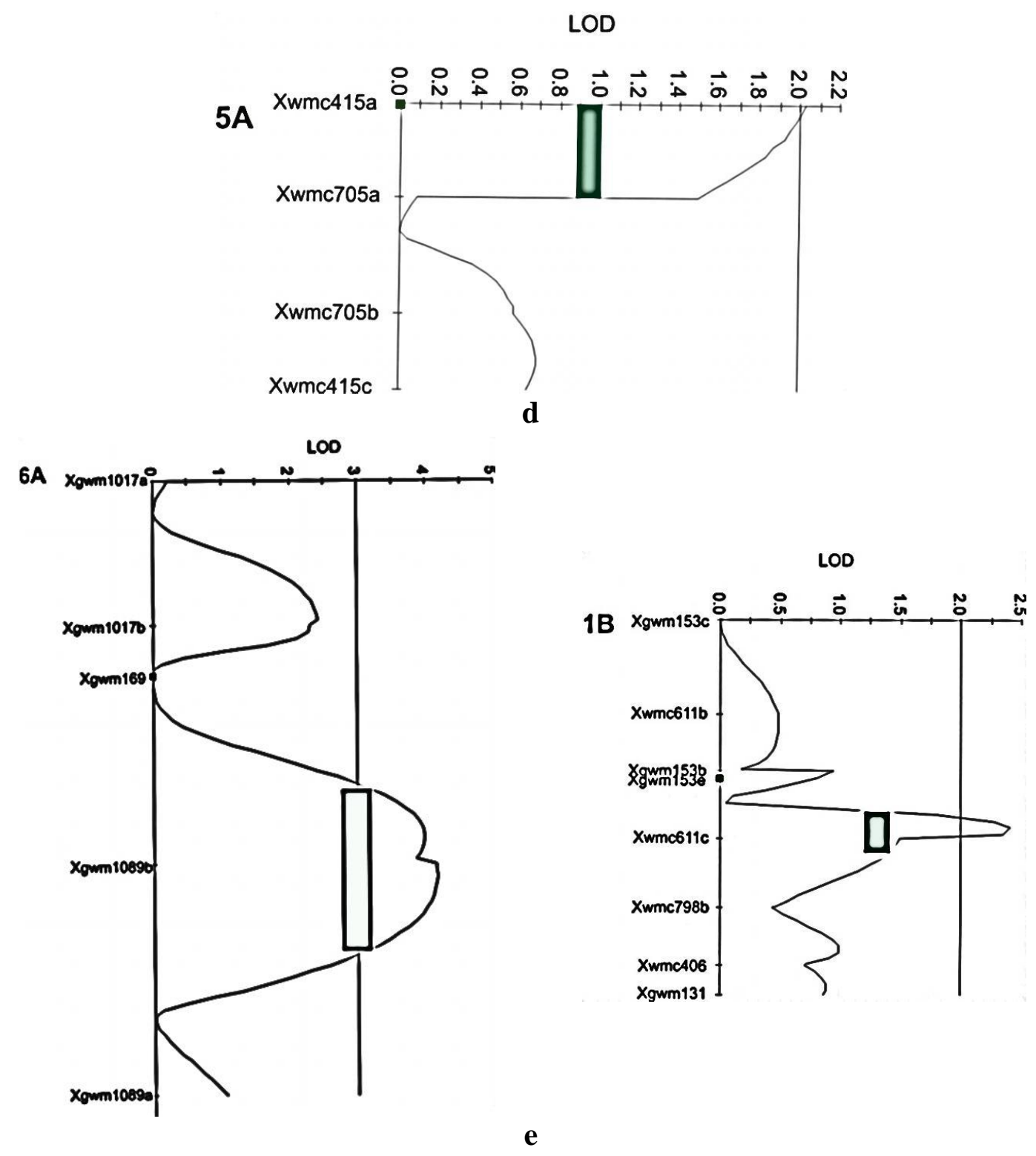

Figure 3. Multiple QTL Mapping (MQM) for the 84 DHs population. (a) Days to heading-fieldtunnel. (b) Days to physiological maturity-field. (c) Spike length-field and tunnel. (d) Thousand grain weight-tunnel. (e) Grain per spike-field and tunnel

\section{Clustering of QTLs for interval mapping}

During current study, the different QTLs were found (Fig. 4). Two clusters of QTLs were detected on 6A chromosome, which covered almost all part of it. First group contained QTLs for (DH) under field conditions, (DPM) under field conditions, Spike length under field conditions, covered the short arm of chromosome. The second group contained QTLs for (DH) under field conditions and (DPM) under field conditions, which covered the long arm of chromosome. On 2D chromosome, two groups of QTLs were found. First group of QTLs consisted of (DH) under field conditions and DPM under field conditions. The second group consisted of four QTLs for DPM under field conditions and DH under field conditions. 
6A

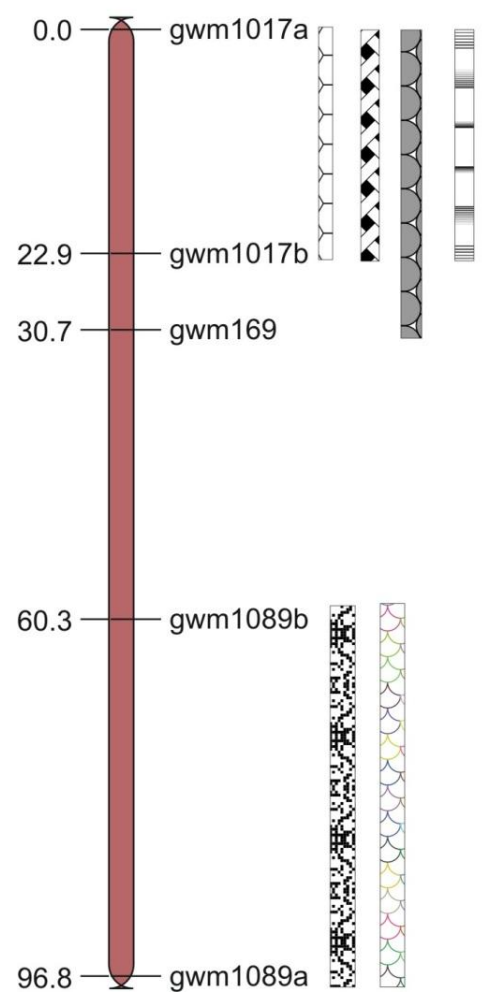

2D

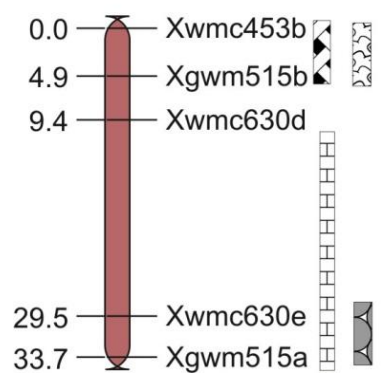

DH-Field-1
DPM-Field-1

G/S-Field-1

Sp.L.Field-1 Ћ"

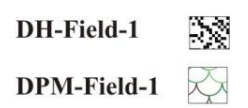

DH-Field-1

DPM-Field-1

DPM-Field-1

DH-Field-1 4

Figure 4. Clustering of QTLs for the 84 DHs population (IM - interval mapping)

\title{
Clustering of QTLs for MQM mapping
}

A group of QTLs was detected on 2D chromosome for different traits. This cluster consisted of QTLs for DH under control and stress conditions and DPM under control conditions (Fig. 5).

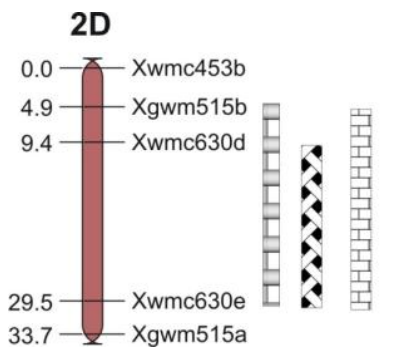

\author{
DH-Field-1 \\ DH-Tunnel-1 \\ DPM-Field-1 田
}

Figure 5. Clustering of QTLs for the $84 \mathrm{DH}$ s population (MQM-Multiple QTL Mapping) 


\section{Discussion}

These are molecular advances, which made it possible to detect chromosomal regions containing genes for quantitative traits. Bread wheat (Triticum aestivum L.) is the staple food of our country and most part of the country is drought prone area so the yield of wheat is badly affected by environmental stress. According to International Water Management Institute (IWMI), wheat production of South Asia will reduce by $50 \%$ by 2050 (de Fraiture et al., 2007). The main objective of the study was to trace such lines which are drought tolerant and can produce improved yield in drought prone areas of the country. Hexaploid wheat has complex genome with three types of genome A, B and D. At the time of wheat evoluation three types of plants contribute A, B and D genomes. At that time, Ae tauschii is D genome donar and diversity of this plant was very less as compared to two genome contributing plants (Dubcovsky and Dvorak, 2007) limiting its ability for its own evolutionary progress. Few genes of Ae tauschii were found for the development of new wheat cultivars, which forced the breeders to collect the accession of Ae. tauschii from different parts of the world and used these accessions to produce genetic diversity in wheat genome (Sohail et al., 2011). Ae. tauschii is the specie which contributes characteristics of biotic and abiotic to wheat genome. Ae. tauschii accessions have D-genome diversity. CIMMYT (International Center for Maize and Wheat improvement) incorporated this diversity of Ae. tauschii in elite durum lines and resynthesized the wheat by crossing the Ae. tauschii and durum lines (Trethowan and Mujeeb-Kazi, 2008). Synthetic wheat lines are stress tolerant so these lines have ability to overcome stress and better yield under drought stress conditions. During field and tunnel experiments, drought-mapping populations presented extensive segregation as compared to the SH 349 and Opata for most traits under consideration. Recombination events were evidenced by improved offspring as compared to their parents (Zhuang et al., 1997). The mapping population displayed a usual dissemination for drought tolerance of maximum yield components with a great extent of transgressive segregation (Fig. 1). All traits showed Normal distribution during the experiment. Transgressive segregation was displayed by all traits in both directions during the analysis of frequency distribution. Polygenic inheritance was observed as the individual lines showed lower and higher values as compare to the parental lines (Kearsey and Pooni, 1996). Transgressive segregation and continuous variation are the two evident attributes of polygenic inheritance (Poehlman and Sleper, 1995). From Figure 1, it is cleared that DH and DPM are polygenic inheritance traits and showed normal distribution with transgressive segregation. It is necessary to detect QTLs that the parents should be of contrasting characters under consideration so parents were selected on contrasting characters of interest. For determination of QTLs, it is necessary that major variation exist between the descendant lines.

Table 3 shows the exact parental positions and ranges. Two-factor factorial analysis of variance was used to identify the interaction between the genotypes and treatments. Significant interactions occurred among all genotypes and treatments (Table 4). The Pearson coefficient was used to find out significant correlation between traits of interest. They showed different increasing or decreasing values according to control and stress conditions (Table 4). The major interaction may be because of environment and genotype interaction, which results in obvious alterations. Significant interactions were observed in genotypes and treatments at $\alpha 0.05$. Supporting results were found during the El-Feki (2010) experiment, who found out significant $(\mathrm{P} \leq 0.05)$ correlations in four environmental conditions over two years between grain yield and plant height and 
average kernel weight. A research also carried out by Narasimhamoorthy et al. (2006) who found a significant $(\mathrm{P} \leq 0.05)$ correlation between plant height, average kernel weight and test weight under two environmental conditions. Same results were also found during the experiment of Butler et al. (2005) for correlations of these traits under two environmental conditions. During the recent study, few yield components showed significant correlation with each other and rest of traits showed non-significant results.

Table 3. Basic statistics for each yield component trait, (field and tunnel experiment) from parents and DHs between individual for control and drought treatments

\begin{tabular}{c|c|c|c|c|c|c|c|c|c|c|c}
\hline Trait & Mean & Minimum & Maximum & Range & Variance & Std. Dev. & Coef. Var. & Skew & Kurtosis & Opata & SH-349 \\
\hline DH-C & 117.66 & 108.00 & 145.00 & 37.00 & 32.25 & 5.68 & 4.83 & 1.3164 & 4.4003 & 121 & 145 \\
DH-S & 119.04 & 104.00 & 155.00 & 51.00 & 126.58 & 11.25 & 9.45 & -3.5053 & 4.878 & 134 & 155 \\
DPM-C & 146.60 & 135.00 & 160.00 & 26.00 & 46.91 & 7 & 5.01 & 0.0311 & -1.3952 & 145 & 161 \\
DPM-S & 152.11 & 113.00 & 175.00 & 63.00 & 116.95 & 11.67 & 7.02 & -5.4634 & 3.154 & 162 & 174 \\
PH-C & 126.37 & 81.00 & 156.30 & 75.30 & 198.36 & 14.08 & 11.15 & -0.5067 & 0.5626 & 114.5 & 129 \\
PH-S & 75.46 & 36.75 & 131.00 & 94.25 & 223.71 & 14.96 & 19.82 & -0.5453 & 3.1250 & 71.25 & 95 \\
Sp.L-C & 11.44 & 7.30 & 16.20 & 8.90 & 3.35 & 1.83 & 16.01 & 0.2281 & 0.0363 & 14 & 9.5 \\
Sp.L-S & 10.00 & 2.50 & 15.25 & 12.75 & 4.16 & 2.04 & 20.39 & -1.4520 & 3.6083 & 9 & 6.75 \\
G/S-C & 45.78 & 21.00 & 79.30 & 58.30 & 157.45 & 12.55 & 27.41 & 0.3713 & -0.1349 & 55 & 43 \\
G/S-S & 19.56 & 1.20 & 55.00 & 53.80 & 130.44 & 11.42 & 58.39 & 0.3707 & -0.1032 & 31 & 22 \\
TGW-C & 34.13 & 1.50 & 51.00 & 49.50 & 69.62 & 8.34 & 24.45 & -1.0098 & 2.0317 & 35 & 51 \\
TGW-S & 23.47 & 0.58 & 36.77 & 36.19 & 75.55 & 8.69 & 37.04 & -1.0047 & 0.2014 & 25 & 35 \\
\hline
\end{tabular}

DH (n) (Days to Heading), DPM (n) (Days to Physiological Maturity), PH (cm) (Plant Height), Sp. L.(cm) (Spike length), G/S (n) (Grain per Spike), TGW (gm) (Thousand Grain Weight), C (Control) and S (Stress)

Table 4. Two factor factorial analysis of variance for each yield component trait (field and tunnel experiment) from parents and DHs between individual for control and drought treatments

\begin{tabular}{c|c|c|c|c|c}
\hline Trait & Source & DF & SS & MS & P \\
\hline DH & LINE & 85 & 38492.20 & 452.85 & 0.00 \\
& TREAT*LINE & 85 & 37344.60 & 439.35 & 0.00 \\
& TREAT & 1 & 1466.86 & 1466.86 & 0.00 \\
\hline DPM & LINE & 85 & 57022.4 & 670.852 & 0.00 \\
& TREAT*LINE & 85 & 51678.1 & 607.978 & 0.00 \\
& TREAT & 1 & 1466.86 & 1466.86 & 0.00 \\
\hline PH & LINE & 85 & 86334.80 & 1015.70 & 0.00 \\
& TREAT*LINE & 85 & 37127.60 & 436.80 & 0.00 \\
& TREAT & 1 & 95472.00 & 95472.00 & 0.00 \\
\hline G/S & LINE & 85 & 42410.40 & 498.95 & 0.00 \\
& TREAT*LINE & 85 & 33496.60 & 394.08 & 0.00 \\
& TREAT & 1 & 300.23 & 300.23 & 0.00 \\
\hline Sp. L & LINE & 85 & 1552.49 & 18.27 & 0.00 \\
& TREAT*LINE & 85 & 653.95 & 7.69 & 0.00 \\
& TREAT & 1 & 15484.50 & 15484.50 & 0.00 \\
\hline TGW & LINE & 85 & 21346.40 & 251.13 & 0.00 \\
& TREAT*LINE & 85 & 17406.80 & 204.79 & 0.00 \\
\hline
\end{tabular}

DH (n) (Days to Heading), DPM (n) (Days to Physiological Maturity), PH (cm) (Plant Height), Sp. L. (cm) (Spike length), G/S (n) (Grain per Spike), TGW (gm) (Thousand Grain Weight), C (Control) and S (Stress) 
For the growth and development of plants, climatic factors play a very important role. Under stress conditions, morphological, physiological and biochemical changes occurred in plants, which ultimately affect growth and yield of plants. QTLs detected by Interval Mapping are mentioned in Table 5. Days to heading, is a very crucial stage in wheat growth and development as it is a complex trait and is controlled by many genes at one time. There is variation in day to heading time, which enables plants to grow under diverse environmental conditions. Four QTLs that affected days to heading were detected under field experiment with LOD values 7.69, 3.89, 1.91 and 2.00 on 2D and 6A chromosome respectively. Alleles for two QTLs contributed by Opata and alleles for two QTLs contributed by SH349. First two QTLs were very important, having values 7.69 and 3.89, which were major QTLs. Narasimhamoorthy et al. (2006) reported a QTL for DH on 2D chromosome, while recent findings were also supported by the study and QTLs for DH were reported on 2D and 6A chromosome and results for 6A were supported by Huang et al. (2003).

Table 5. QTLs detected by multiple QTL mapping of a DH population Opata $\times$ SH349. QTL were identified by interval mapping and significance was recognized at an LOD threshold following 1,000 permutations (in brackets) (different threshold for each trait). Size of the effect and phenotypic variation explained $\left(R^{2}\right)$ are also presented

\begin{tabular}{|c|c|c|c|c|c|c|c|c|c|}
\hline Sr \# & Name of QTL & QTL interval ${ }^{\mathrm{a}}$ & Peak marker & $\mathbf{C r}^{\mathrm{b}}$ & Trait & Env & LOD & Adtv eft ${ }^{\mathrm{c}}$ & $\mathbf{R}^{2 \mathrm{~d}}(\%)$ \\
\hline 1 & QDH.C.MQ.wwc-2D & gwm515b-wmc630e & wmc630d & $2 \mathrm{D}$ & $\mathrm{DH}$ & Field & $\begin{array}{l}6.93 \\
(3.4)\end{array}$ & 2.91 & 35.7 \\
\hline 2 & QDH.S.MQ.wwc-2D & wmc630d-wmc630e & wmc630d & $2 \mathrm{D}$ & $\mathrm{DH}$ & Tunnel & 3.14 & -9.7 & 72.1 \\
\hline 3 & QDPM.C.MQ.wwc-2D & gwm515b-wmc630e & wmc630d & $2 \mathrm{D}$ & DPM & Field & $\begin{array}{c}9.39 \\
(3.56)\end{array}$ & 5.94 & 79.4 \\
\hline 4 & QSp.L.C.MQ.wwc-4A & gwm160-gwm1081 & wmc 262 & $4 \mathrm{~A}$ & Sp-L & Field & $\begin{array}{c}3.45 \\
(2.56)\end{array}$ & 0.76 & 17.7 \\
\hline 5 & QSp.L.S.MQ.wwc-7A & gwm60b-wmc826b & wmc826c & $7 \mathrm{~A}$ & Sp-L & Tunnel & 4.93 & -1.86 & 31.9 \\
\hline 6 & $Q T G W . S . M Q . w w c-5 A$ & wmc415a-wmc705a & wmc415a & $5 \mathrm{~A}$ & TGW & Tunnel & $\begin{array}{l}2.03 \\
(2.2)\end{array}$ & -2.94 & 10.8 \\
\hline 7 & $Q G / S . C . M Q . w w c-6 A$ & gwm169-gwm1089a & gwm1089b & $6 \mathrm{~A}$ & $\mathrm{G} / \mathrm{S}$ & Field & $\begin{array}{c}3.98 \\
(2.89)\end{array}$ & -6.75 & 28.8 \\
\hline 8 & $Q G / S . S . M Q . w w c-1 B$ & gwm153e-wmc611c & gwm153e & $1 \mathrm{~B}$ & $\mathrm{G} / \mathrm{S}$ & Tunnel & 2.41 & -5.99 & 27.2 \\
\hline
\end{tabular}

a: Marker interval where the QTL has been detected. b: Chr Chromosome. c: Effects on the examined characters of the alleles from the 'Opata'. d: R2 (\%) is the quantity of phenotypic variation clarified by the QTL

The duration of maturity of any crop is decreased by drought stress and differs with genotype, because of their inherent nature. A QTL on chromosomes 1B affected days to physiological maturity having LOD value 3.06, which was a major QTL, and the allele for this QTL was contributed by SH349 and $80.4 \% \mathrm{R}^{2}$ values. Results found during the previous study by Peleg et al. (2009) were in agreement with the present study as QTL for DPM was reported on 1B chromosome. Two QTLs for G/S were found by interval mapping under control conditions having values 2.31 and 2.43 on $6 \mathrm{~A}$ and $7 \mathrm{~B}$ chromosomes respectively. A QTL was found on 6A chromosome by Peleg et al. (2011). No supporting reference was found for QTL discovered on 7B, therefore, it is a novel QTL found during our research. The allele for this QTL was contributed by SH349 with $13.1 \mathrm{R}^{2}$ value. Under drought conditions, a minor QTL was found on 5A 
chromosome with a LOD value 2.03 for thousand-grain weight by interval mapping. Peleg et al. (2011) and Dashti et al. (2007) found same results for thousand-grain weight on $5 \mathrm{~A}$ chromosome under stress conditions. A QTL was found on $6 \mathrm{~A}$ chromosome under control conditions having a LOD value 2.02. No supporting reference was found for QTL found for Spike length so it is also a novel QTL.

Multiple QTL Mapping (MQM) was used to get more refine results for QTLs obtained by Interval mapping. Two QTLs were found on 2D chromosome under control and stress conditions for days to heading. These two QTLs were more reliable and consistent as these were found under control and stress conditions and peak marker and chromosome were same. A very little work has been done on yield and yield components of wheat, as wheat genome is very complex and mainly under water stress conditions (Quarrie et al., 2005). They reported QTLs for days to heading on 2D chromosome. A major QTL for days to physiological maturity was detected on 2D chromosome with LOD 9.39 value during the recent study by MQM mapping. Same results were found during the previous study by Huang et al. (2006). Wheat spike grows from the axils of main shoot leaves. The number and length of spike differs from genotype to genotype and mainly depends on ecological situations. For spike length, a major QTL was found on 4A chromosome under control conditions with 3.45 LOD value. A second QTL for spike length was found under stress conditions on 7A chromosome with a LOD value 4.93. Previous results of Chu et al. (2008) and Jantasuriyarat et al. (2004) were in agreement with the recent study.

The main aim of the present study is to improve the existing high yielding drought sensitive wheat cultivars. During the last twenty years, QTL analysis largely used to detect QTLs associated with complex traits, such as yield and yield components under drought stress (Ain et al., 2015). These traits are polygenic traits and are controlled by many genes at a time so it is very difficult to clone such QTL of the traits under drought stress. Only a few QTLs have been utilized in plant molecular breeding for wheat and none QTL is clone yet (Fleury et al., 2010). As discussed above, the major QTLs found during the study can be used for molecular breeding. Such lines can be grown under water stress conditions. Two major QTLs for DH were found by interval mapping under control conditions having LOD values 7.69 and 3.89 respectively. These QTLs are of great importance as these were located on $2 \mathrm{D}$ chromosome as it is difficult to find polymorphism for D genome so we can use these QTLs in marker-assisted selection. Additive effect showed that the allele for the second QTL for DH was contributed by SH349 (drought tolerant parent) with $21.4 \%$ phenotypic variation. Again, drought tolerant parent (SH349) contributed alleles for third major QTL with 3.06 LOD value and $80.4 \%$ phenotypic variation. QTLs found by the MQM are more reliable and precise as these were obtained after the interval mapping. Eight QTLs were found during the present study and out of which six were major QTLs. Highest LOD value 9.39 was noted for DPM with $79.4 \%$ phenotypic variation under control conditions on 2D chromosome. After that, second major QTL was reported on 2D chromosome for DH with 6.93 LOD value with $35.7 \%$ phenotypic variation. Third major QTL was found on 7A chromosome with 4.93 LOD value and allele for this QTL was contributed by SH349. 7A chromosome is considered as important chromosome for yield and yield component (Quarrie et al., 2006). Fourth QTL was found on 6A chromosome with 3.98 LOD value for G/S and again allele for this QTL was contributed by SH349. Same results were found during previous study by Peleg et al. (2011) who reported QTL for $\mathrm{G} / \mathrm{S}$ on $6 \mathrm{~A}$ chromosome. Last two major QTLs were found on 4A and 2D chromosomes 
with 3.45 and 3.14 LOD values respectively. These QTLs are very important as we can exploit in future for molecular breeding especially the QTLs, which were located on 2D chromosome with high LOD value. A minor QTL for thousand-grain weight was found during the study on 5A chromosome with 2.15 LOD values. QTL for TGW on 5A chromosome was reported during the previous study by Wang et al. (2009) and Peleg et al. (2011). Another minor QTL for G/S was found on 1B chromosome with 2.41 LOD value and additive effect -5.99 , means alleles contributed by SH349. In previous study, QTL was reported on 1B chromosome by Dashti et al. (2007). Five drought tolerant wheat lines were identified based on a thousand-grain weight, ranging from 49 to $62 \mathrm{~g}$ (Table 6).

Table 6. Drought tolerant lines

\begin{tabular}{cccc}
\hline Sr no & Line & Thousand Grain Weight $\mathbf{( g m )}$ & Grain per spike (n) \\
\hline 1 & 54 & 62.0 & 26 \\
2 & 56 & 62.0 & 45 \\
3 & 34 & 59.0 & 24 \\
4 & 59 & 55.6 & 55 \\
5 & 18 & 49.0 & 26 \\
\hline Parent 1 & Opata & 22.0 & 31 \\
Parent 2 & SH349 & 45.0 & 23 \\
\hline
\end{tabular}

\section{Conclusion}

The present study was targeted to dissect the complex quantitative inheritance of yield component of wheat under control and drought stress conditions. Genotyping was executed using SSR markers. Major and minor QTLs were recognized for different yield components. One QTL for thousand-grain weight was found by interval mapping on 5A chromosome while four QTLs were found by multiple QTL mapping under drought stress conditions on 2D, 7A, 5A and 1B chromosome. These identified QTLs are of primary importance for high resolution mapping in synthetic hexaploid wheat. These identified genomic loci were considered auxiliary as they were saturated with molecular markers for accurate localization of QTLs leading to the inheritance of these polygenic traits. Further, genetic and transcriptome characterization of this mapping population could be supportive for the identification of genomic regions closely associated with drought stress resistance. Introgression of these resistant regions into adapted genetic backgrounds through marker-assisted selection is a promising tool for plant evolution, gene cloning and transgenic crop improvement.

Acknowledgements. Higher Education Commission Pakistan is acknowledged for awarding HEC Indigenous 5000 Fellowship Program Batch-IV and IRSIP (International Research Support Initiative Program) scholarship for carrying out this study.

Author contributions. Sammer Fatima and Muhammad Arshad conceived and designed the experiments; Shamim Akhtar, Sunbal Khalil Chaudhari and Muhammad Sajjad Iqbal performed the experiments; Muhammad Akbar and Rehana Kausar analyzed the data; Muhammad Shoaib Amjad and Mehmooda Munazir wrote the paper.

Conflicts of interest. There is no conflict of interest among authors. 


\section{REFERENCES}

[1] Ahmed, N., Chowdhry, M. A., Khaliq, I., Maekawa, M. (2007): The inheritance of yield and yield components of five wheat hybrid populations under drought conditions. Indonesian J Agric Sci 8: 53-59.

[2] Ain, Q., Rasheed, A., Anwar, A., Mahmood, T., Imtiaz, M., Mahmood, T. (2015): Genome-wide association for grain yield under rainfed conditions in historical wheat cultivars from Pakistan. - Front Plant Sci. Frontiers Media S. A. 6: 743.

[3] Bennett, M. D., Smith, J. B. (1976): Nuclear DNA amounts in angiosperms. - Philos Trans R Soc Lond B 274: 227-274.

[4] Butler, J. M., Byrne, P. F., Mohammadi, V., Chapman, P. L., Haley, S. D. (2005): Agronomic performance of Rht alleles in a spring wheat population across a range of moisture levels. - Crop Sci 45: 939-947.

[5] Chu, C. G., Xu, S. S., Friesen, T. L., Faris, J. D. (2008): Whole genome mapping in a wheat doubled haploid population using SSRs and TRAPs and the identification of QTL for agronomic traits. - Mol Breed 22: 251-266.

[6] Churchill, G. A., Doerge, R. W. (1994): Empirical threshold values for quantitative trait mapping. - Genetics 138: 963-971.

[7] Dashti, H., Yazdi-Samadi, B., Ghannadha, M., Naghavi, M. R., Quarri, S. (2007): QTL analysis for drought resistance in wheat using doubled haploid lines. - Int J Agri Biol 9: 98-102.

[8] De-Fraiture, C., Smakhtin, V., Bossio, D., McCornick, P., Hoanh, C., Noble, A., Molden, D., Gichuki, F., Giordano, M., Finlayson, M., Turral, H. (2007): Facing climate change by securing water for food livelihoods and ecosystems. - Journal of Semi-Arid Tropical Agricultural Research 4(1): 1-12.

[9] Del Blanco, I. A., Rajaram, S., Kronstad, W. E., Reynolds, M. P. (2000): Physiological performance of synthetic hexaploid wheat-derived populations. - Crop Sci 40: 12571263.

[10] Del Blanco, I. A., Rajaram, S., Kronstad, W. E. (2001): Agronomic potential of synthetic hexaploid wheat-derived populations. - Crop Sci 41: 670-676.

[11] Din, K., Singh, R. M. (2005): Grain filling duration; an important trait in wheat improvement. - SAIC Newsletter 15: 4-5.

[12] Dreisigacker, S., Zhang, P., Ginkel, M. V., Warburton, M., Hoisington, D., Bohn, M., Melchinger, A. E. (2004): SSR and pedigree analyses of genetic diversity among CIMMYT wheat lines targeted to different mega-environments. - Crop Sci 44: 381-388.

[13] Dubcovsky, J., M. C., Luo, G. Y., Zhong, R., Brandsteitter, A., Desai, A., Kilian, A., Kleinhofs, J., Dvorak. (1996): Genetic map of diploid wheat, Triticum monococcum L. and its comparison with maps of Hordeum vulgare L. - Genet. 143: 983-999.

[14] El-Feki, W. (2010): Mapping quantitative trait loci for bread making quality and agronomic traits in winter wheat under different soil moisture levels. - Ph.D. Dissertation Colorado State Univ., Fort Collins.

[15] Fatima, S., Arshad, M., Qureshi, R. (2014): QTL mapping for physiological maturity in synthetic hexaploid wheat (Triticum aestivum L.) under drought stress. - Pure and Appl Biol 3: 22-28.

[16] Fischer, R. A. (1985): Number of kernels in wheat crops and the influence of solar radiation and temperature. - J Agric Sci 105: 447-461.

[17] Fleury, D., Jefferies, S., Kuchel, H., Langridge, P. (2010): Genetic and genomic tools to improve drought tolerance in wheat. - J Exp Bot 61: 3211-3222.

[18] Government of Pakistan (2012): Chapter No. 2. - Agric Econ Surv 2011(12): 21-24.

[19] Government of Pakistan (2017): Chapter No. 2. - Agric Econ Surv 2016(17): 23-24.

[20] Gupta, P. K., Balyan, H. S., Edwards, K. J., Isaac, P., Korzun, V., Roder, M., Gautier, M. F., Joudrier, P., Schlatter, A. R., Dubcovsky, J., De-La-Pena, R. C., Khairallah, M., Penner, G., Hayden, M. J., Sharp, P., Keller, B., Wang, R. C. C., Hardouin, J. P., Jack, P., 
Leroy, P. (2002): Genetic mapping of 66 new microsatellite (SSR) loci in bread wheat. Theor Appl Genet 105: 413-422.

[21] Guyomarc'h, H., Sourdille, P., Charmet, G., Edwards, K. J., Bernard, M. (2002): Characterization of polymorphic microsatellite markers from Aegilops taushii and transferability to the D-genome of bread wheat. - Theor Appl Genet 104: 1164-1172.

[22] Holmberg, N., Bulow, L. (1998): Improving stress tolerance in plants by gene transfer. Trends Plant Sci 3: 61-66.

[23] Hossain, A., Sarker, MAZ., Saifuzzaman, M., Akhter, M. M., Mandal, M. S. N. (2009): Effect of sowing dates on yield of wheat varieties and lines developed since 1998. Bangladesh J Prog Sci Tech 7: 5-8.

[24] Hossain, A., Sarker, M. A. Z., Hakim, M. A., Lozovskaya, M. V., Zvolinsky, V. P. (2011): Effect of temperature on yield and some agronomic characters of spring wheat (Triticum aestivum L.) genotypes. - Int J Agri Res Innov Tech 1: 44-54.

[25] Hossain, A., Lozovskaya, M. V., Zvolinsky, V. P., Teixeira-da-Silva, J. A. (2012a): Effect of soil and climatic conditions on yield related components performance of spring wheat (Triticum aestivum L.) varieties in northern Bangladesh. - J Fund Appl Sci 39: 6978.

[26] Hossain, A., Lozovskaya, M. V., Zvolinsky, V. P., Teixeira-da-Silva, J. A. (2012b): Effect of soil and climatic conditions on phenology of spring wheat varieties in northern Bangladesh. - J Fund Appl Sci 39: 78-86.

[27] Hossain, A., Teixeira-da-Silva, J. A., Lozovskaya, M. V., Zvolinsky, V. P. (2012c): The effect of high temperature stress on the phenology, growth and yield of five wheat (Triticum aestivum L.) genotypes. - The Asian Austr J Plant Sci Biotech 6: 14-23.

[28] Huang, X. Q., Goster, H., Ganal, M. W., Roder, M. S. (2003): Advanced backcross QTL analysis for the identification of quantitative trait loci alleles from wild relatives of wheat (Triticum aestivum L.). - Theor Appl Genet 106: 1379-1389.

[29] Huang, X. Q., Kempf, H., Ganal, M. W., Roder, M. S. (2004): Advanced backcross QTL analysis in progenies derived from a cross between a German elite winter wheat variety and a synthetic wheat (Triticum aestivum L.). - Theor Appl Genet 109: 933-943.

[30] Huang, X. Q., Cloutier, S., Lycar, L., Radovanovic, N., Humphreys, D. G., Noll, J. S., Somers, D. J., Brown, P. D. (2006): Molecular detection of QTLs for agronomic and quality traits in a doubled haploid population derived from two Canadian wheats (Triticum aestivum L.). - Theor Appl Genet 113: 753-766.

[31] Huaqi, W., Bouman, B. A. M., Zhao, D., Changgui, W., Moya, P. F. (2002): Aerobic rice in northern China: Opportunities and challenges. - Workshop on Waterwise Rice Production, 8-11 April, IRRI, Los Banos, Philippines.

[32] Ijaz, S., Khan, I. A. (2009): Molecular characterization of wheat germplasm using microsatellite markers. - Genet Mol Res 8: 809-815.

[33] Jantasuriyarat, C., Vales, M. I., Watson, C. J. W., Riera-Lizarazu, O. (2004): Identification and mapping of genetic loci affecting the free-threshing habit and spike compactness in wheat (Triticum aestivum L.). - Theor Appl Genet 108: 261-273.

[34] Jones, C. J., Edwards, K. J., Castiglione, S., Winfield, M. O., Salsa, F., Wiel, C. V. D., Bredemeijer, G. (1997): Reproducibility test of RAPD, AFLP and SSR markers in plants by a network of European laboratories. - Mol Breed 3: 381-390.

[35] Kearsey, M. J., Pooni, H. S. (1996): The Genetical Analysis of Quantitative Traits. Chapman and Hall, Birmingham, U. K.

[36] Mahboob, A. S., Arain, M. A., Khanzada, S., Naqvi, M. H., Dahot, M. U., Nizamani, N. A. (2005): Yield and quality parameters of wheat genotypes as affected by sowing dates and high temperature stress. - Pak J Bot 37: 575-584.

[37] McCouch, S. R., Doerge, R. W. (1995): QTL mapping in rice. - Trends Genet 11: 482487.

[38] Mujeeb-Kazi, A. (2000): Current status of D genome based synthetic hexaploid wheats and the characterization of an elite subset. - Annual Wheat Newsletter 46: 76-79. 
[39] Mujeeb-Kazi, A., Rajaram, S. (2002): Transferring Alien Genes from Related Species and Genera for Wheat Improvement. - In: Curtis, B. C., Rajaram, S., Gómez Macpherson, H. (eds.) Bread Wheat Improvement and Production. FAO, Rome, pp. 199215.

[40] Mujeeb-Kazi, A., A. Gul, M., Farooq, S., Rizwan, I., Ahmad. (2008): Rebirth of synthetic hexaploids with global implications for wheat improvement. - Aust. J. Agric. Res. 59(5): 391-398.

[41] Narasimhamoorthy, B., Gill, A. K., Fritz, B. S., Nelson, J. C., Brown-Guedira, G. L. (2006): Advanced backcross QTL analysis of a hard winter wheat $\mathrm{x}$ synthetic wheat population. - Theor Appl Genet 112: 787-796.

[42] Peleg, Z., Fahima, T., Krugman, T., Abbo, S., Yakir, D., Korol, A. B., Saranga, Y. (2009): Genomic dissection of drought resistance in durum Wheat $\mathrm{x}$ wild emmer wheat recombinant inbreed line population. - Plant Cell and Environ 32: 758-779.

[43] Peleg, Z., Fahima, T., Korol, A. B., Abbo, S., Saranga, Y. (2011): Genetic analysis of wheat domestication and evolution under domestication. - J Expt Bot 62: 5051-5061.

[44] Peng, J. H., Lapitan, N. L. V. (2005): Characterization of EST-derived microsatellites in the wheat genome and development of eSSR markers. - Funct Integr Genome 5: 80-96.

[45] Poehlman, J. M., Sleper, D. A. (1995): Breeding Filed Crops. $4^{\text {th }}$ ed. - Iowa State Univ. Press, Ames.

[46] Quarrie, S. A., Steed, A., Calestani, C., Semikhodskii, A., Lebreton, C., Chinoy, C., Steele, N., Pljevljakusic, D., Waterman, E., Weyen, J., Schondelmaier, J., Habash, D. Z., Farmer, P., Saker, L., Clarkson, D. T., Abugalieva, A., Yessimbekova, M., Turuspekov, Y., Abugalieva, S., Tuberosa, R., Sanguineti, M. C., Hollington, P. A., Aragues, R., Royo, A., Dodig, D. (2005): A high-density genetic map of hexaploid wheat (Triticum aestivum L.) from the cross Chinese Spring X SQ1 and its use to compare QTLs for grain yield across a range of environments. - Theor Appl Genet 110: 865-880.

[47] Quarrie, S. A., Quarrie, S. P., Radosevic, R., Rancic, D., Kaminska, A., Barnes, J. D., Leverington, M., Ceoloni, C., Dodig, D. (2006): Dissecting wheat QTL for yield present in a range of environments: from the QTL to candidate genes. - J Expt Bot 57: 26272637.

[48] Rajaram, S. (2001): Prospects and promise of wheat breeding in the $21^{\text {st }}$ century. Euphytica 119: 3-15.

[49] Rashid, A., Hussain, F., Baig, M. B., Bughio, N. (1994): Soil Fertility Status of Experimental Area at National Agricultural Research Center, Islamabad, Pakistan. Pakistan Agriculture Research Council, Islamabad, Pakistan.

[50] Ray, D. K., Mueller, N. D., West, P. C., Foley, J. A. (2013): Yield trends are insufficient to double global crop production by 2050. - PLoS One 8(6): 66428. DOI: 10.1371/journal.pone.0066428.

[51] Roder, M. S., Korzun, V., Wendehake, K., Plaschke, J., Tixier, M. H., Leroy, P., Ganal, M. W. (1998): A microsatellite map of wheat. - Genetics 149: 2007-2023.

[52] Schmidt, A. L., McIntyre, C. L., Thompson, J., Seymour, N. P., Liu, C. J. (2005): Quantitative trait loci for root lesion nematode (Pratylenchus thornei) resistance in Middle-Eastern landraces and their potential for introgression into Australian bread wheat. - Aust J Agric Res 56: 1059-1068.

[53] Sharp, P. J., Desai, S., Chao, S., Gale, M. D. (1988): Isolation and use of a set of 14 RFLP probes for the identification of each homeologous arm in the Triticeae. - In: Miller, T. E., Koebner, R. M. D. (eds.) Proc $7^{\text {th }}$ Int Wheat Genet Symp IPSR, Cambr Lab, Cambr, England, pp. 639-643.

[54] Sohail, Q., T., Inoue, H., Tanaka, A. E., Eltayeb, Y., Matsuoka, H., Tsujimoto. (2011): Applicability of Aegilops tauschii drought tolerance traits to breeding of hexaploid wheat. - Breed Sci. 61: 347-357.

[55] Somers, J. D., Isaac, P., Edwards, K. (2004): A high-density microsatellite consensus map for bread wheat (Triticum aestivum L.). - Theor Appl Genet 109: 1105-1114. 
[56] Song, Q. J., Shi, J. R., Singh, S., Fickus, E. W., Costa, J. M., Lewis, J., Gill, B. S., Ward, R., Cregan, P. B. (2005): Development and mapping of microsatellite (SSR) markers in wheat. - Theor Appl Genet 110: 550-560.

[57] Sourdille, P., Cadalen, T., Guyomore, H., Snape, H. J. W., Penetant, M. R., Charmet, G., Boeuf, C., Bernard, S., Bernard, M. (2003): An update of the Courtot x Chinse Spring intervarietal molecular marker linkage map for QTL detection of agronomic traits in wheat. - Theor Appl Genet 106: 530-538.

[58] Sun, G. L., Salomon, B., Bothmer, R. V. (1998): Characterization and analysis of microsatellite loci in Elymus caninus (Triticeae: Poaceae). - Theor Appl Genet 96: 676682.

[59] Tuberosa, R., Salvi, S. (2006): Genomics based approaches to improve drought tolerance of crops. - Trends Plant Sci 8: 405-412.

[60] Van, Ooijen, J. W. (2004): MapQTL 5, Software for the Mapping of Quantitative Trait Loci in Experimental Populations. - Kyazma BV, Wageningen.

[61] Van, Ooijen, J. W., Voorips, R. E. (2004): JoinMap Version 3.0, Software for the Calculation of Genetic Linkage Maps. - Kyazma BV, Wageningen.

[62] Wahid, A., Gelani, S., Ashraf, M., Foolad, M. R. (2007): Heat tolerance in plants. An overview. - Environ Exp Bot 61: 199-233.

[63] Xue, S., Zhang, Z., Lin, Z., Kong, Y., Cao, C., Li., H., Yi, M., Mei, H., Zhu, J., Wu, H., Xu, D., Zhao, D., Tian, C., Zhang, Z., Ma. (2008): A high-density intervarietal map of the wheat genome enriched with markers derived from expressed sequence tags. - Theor Appl Genet 117: 181-189.

[64] Young, N. D. (1996): QTL mapping and quantitative disease resistance in plants. - Ann Rev Phytopathol 34: 479-501.

[65] Zhuang, J. Y., Lin, X. N., Lu, J., Qian, H. R., Hittalmani, S., Huang, N., Zheng, K. L. (1997): Analysis of QTL x environment interaction for yield components and plant height in rice. - Theor Appl Genet 95: 799-808.

\section{APPENDIX}

Chi-square test outcome

\begin{tabular}{c|c|c|c}
\hline Sr & SSR & A/B & Chi-square $(\mathbf{p}<\mathbf{0 . 0 5})$ \\
\hline $\mathbf{1}$ & wmc415a-5A-5B & 1.80 & 0.02 \\
\hline $\mathbf{2}$ & wmc415b-5A-5B & 0.87 & 0.02 \\
\hline $\mathbf{3}$ & wmc415c-5A-5B & 0.95 & 0.02 \\
\hline $\mathbf{4}$ & wmc415d-5A-5B & 1.21 & 0.02 \\
\hline $\mathbf{5}$ & wmc415e-5A-5B & 0.84 & 0.02 \\
\hline $\mathbf{6}$ & wmc705a-5A & 1.19 & 0.02 \\
\hline $\mathbf{7}$ & wmc705b-5A & 0.86 & 0.02 \\
\hline $\mathbf{8}$ & wmc611a-1A-1B-7B & 1.29 & 0.03 \\
\hline $\mathbf{9}$ & wmc611b-1A-1B-7B & 1.22 & 0.02 \\
\hline $\mathbf{1 0}$ & wmc611c-1A-1B-7B & 1.58 & 0.03 \\
\hline $\mathbf{1 1}$ & wmc606a-7B-7D & 0.88 & 0.02 \\
\hline $\mathbf{1 2}$ & wmc606b-7B-7D & 1.13 & 0.02 \\
\hline $\mathbf{1 3}$ & wmc606c-7B-7D & 0.84 & 0.02 \\
\hline $\mathbf{1 4}$ & wmc606d-7B-7D & 1.38 & 0.02 \\
\hline $\mathbf{1 5}$ & wmc235a-5B & 1.45 & 0.02 \\
\hline $\mathbf{1 6}$ & wmc235b-5B & 0.57 & 0.03
\end{tabular}




\begin{tabular}{|c|c|c|c|}
\hline 17 & gwm1040-6A & 6.64 & 0.02 \\
\hline 18 & gwm160-4A & 0.95 & 0.02 \\
\hline 19 & gwm210a-2A-2B-2D-1B & 0.95 & 0.02 \\
\hline 20 & gwm210b-2A-2B-2D-1B & 4.25 & 0.02 \\
\hline 21 & gwm210c-2A-2B-2D-1B & 1.15 & 0.02 \\
\hline 22 & gwm1089a-6A & 3.37 & 0.02 \\
\hline 23 & gwm1089b-6A & 1.24 & 0.02 \\
\hline 24 & wmc453a-2A-2B-2D & 1.48 & 0.02 \\
\hline 25 & wmc453b-2A-2B-2D & 1.08 & 0.02 \\
\hline 26 & wmc $453 \mathrm{c}-2 \mathrm{~A}-2 \mathrm{~B}-2 \mathrm{D}$ & 2.07 & 0.02 \\
\hline 27 & wmc453d-2A-2B-2D & 1.31 & 0.02 \\
\hline 28 & wmc718a-4A & 1.67 & 0.03 \\
\hline 29 & wmc718b-4A & 0.01 & 0.02 \\
\hline 30 & wmc $718 \mathrm{c}-4 \mathrm{~A}$ & 0.93 & 0.02 \\
\hline 31 & gwm60a-7A-7B & 4.06 & 0.02 \\
\hline 32 & gwm60b-7A-7B & 1.66 & 0.03 \\
\hline 33 & wmc826a-1A-4B-7A & 0.16 & 0.03 \\
\hline 34 & wmc826b-1A-4B-7A & 2.81 & 0.03 \\
\hline 35 & wmc826c-1A-4B-7A & 1.79 & 0.02 \\
\hline 36 & wmc826d-1A-4B-7A & 1.11 & 0.03 \\
\hline 37 & wmc262a-4A & 0.93 & 0.02 \\
\hline 38 & wmc $262 \mathrm{~b}-4 \mathrm{~A}$ & 0.98 & 0.02 \\
\hline 39 & wmc406-1B & 0.70 & 0.03 \\
\hline 40 & w630a2A7D2D5D5B1A5A & 0.60 & 0.03 \\
\hline 41 & w630b2A7D2D5D5B1A5A & 1.21 & 0.03 \\
\hline 42 & w630c2A7D2D5D5B1A5A & 6.20 & 0.03 \\
\hline 43 & w630d2A7D2D5D5B1A5A & 1.06 & 0.03 \\
\hline 44 & w630e2A7D2D5D5B1A5A & 2.04 & 0.03 \\
\hline 45 & w630f2A7D2D5D5B1A5A & 0.24 & 0.03 \\
\hline 46 & w630g2A7D2D5D5B1A5A & 2.04 & 0.03 \\
\hline 47 & w630h2A7D2D5D5B1A5A & 0.27 & 0.03 \\
\hline 48 & gwm126-5A & 0.85 & 0.03 \\
\hline 49 & wmc798a-1B & 2.32 & 0.03 \\
\hline 50 & wmc798b-1B & 1.12 & 0.03 \\
\hline 51 & gwm122a-2A & 3.11 & 0.03 \\
\hline 52 & gwm122b-2A & 1.24 & 0.03 \\
\hline 53 & gwm195a-7B & 0.51 & 0.03 \\
\hline 54 & gwm195b-7B & 1.35 & 0.03 \\
\hline 55 & gwm148-3B-2B & 1.96 & 0.03 \\
\hline 56 & gwm108-3B & 1.38 & 0.03 \\
\hline 57 & wmc398-6A-6B & 0.67 & 0.03 \\
\hline 58 & gwm698a-7A & 1.12 & 0.04 \\
\hline 59 & gwm698b-7A & 0.69 & 0.03 \\
\hline 60 & gwm1017a-6A & 1.13 & 0.03 \\
\hline 61 & gwm 1017b-6A & 0.49 & 0.03 \\
\hline
\end{tabular}




\begin{tabular}{l|c|c|c}
\hline $\mathbf{6 2}$ & gwm131-3B-6B-1B & 0.69 & 0.02 \\
\hline $\mathbf{6 3}$ & gwm169-6A & 0.59 & 0.03 \\
\hline $\mathbf{6 4}$ & gwm146a-7B & 1.06 & 0.03 \\
\hline $\mathbf{6 5}$ & gwm146b-7B & 2.13 & 0.03 \\
\hline $\mathbf{6 6}$ & gwm146c-7B & 0.77 & 0.03 \\
\hline $\mathbf{6 7}$ & gwm1081-4A & 2.71 & 0.03 \\
\hline $\mathbf{6 8}$ & gwm153a-1B & 0.05 & 0.02 \\
\hline $\mathbf{6 9}$ & gwm153b-1B & 0.02 \\
\hline $\mathbf{7 0}$ & gwm153c-1B & 1.80 & 0.02 \\
\hline $\mathbf{7 1}$ & gwm153d-1B & 3.94 & 0.02 \\
\hline $\mathbf{7 2}$ & gwm153e-1B & 26.33 & 0.02 \\
\hline $\mathbf{7 3}$ & gwm153f-1B & 1.71 & 0.02 \\
\hline $\mathbf{7 4}$ & gwm515a-2A-2D & 19.50 & 0.02 \\
\hline $\mathbf{7 5}$ & gwm515b-2A-2D & 1.90 & 0.02 \\
\hline $\mathbf{7 6}$ & gwm515c-2A-2D & 0.89 & 0.03 \\
\hline $\mathbf{7 7}$ & gwm515d-2A-2D & 1.71 & 0.02 \\
\hline $\mathbf{7 8}$ & gwm285-3B & 0.08 & 0.03 \\
\hline $\mathbf{7 9}$ & gwm495-4B & 0.82 & 0.03 \\
\hline & & 0.67 & \\
\hline
\end{tabular}

